\title{
Towards the updated Italian seismic risk assessment: exposure and vulnerability modelling
}

\author{
Angelo Masi ${ }^{1}$ - Sergio Lagomarsino ${ }^{2}$ - Mauro Dolce ${ }^{3} \cdot$ Vincenzo Manfredi $^{1}$. \\ Daria Ottonelli ${ }^{2}$
}

Received: 3 September 2020 / Accepted: 12 February 2021 / Published online: 1 March 2021

(c) The Author(s) 2021

\begin{abstract}
Within the 2019-2021 research agreement between the Civil Protection Department (DPC) and the Network of University Laboratories for Earthquake Engineering (ReLUIS), the work package WP4 "Seismic Risk Maps-MARS" is specifically devoted to update the 2018 release of the Italian National Seismic Risk Assessment. To this end, the previously considered models of hazard, exposure and vulnerability will be critically reviewed and updated by taking advantage also from the results deriving from other WPs of the DPCReLUIS research project. In the present paper some of the most relevant aspects that are being introduced in the development of the new Italian risk maps have been described and shortly analysed. First, a significant upgrade of the vulnerability model implemented in the new version of the platform used for risk calculation (IRMA) is proposed, where reference to the six EMS-98 classes is made also considering regional vulnerability features. Further, empirical data from observed real damage are integrated with results from numerical simulations (mechanical approach), in particular for reinforced concrete buildings. Finally, some special construction types such as schools, churches and bridges are included in order to provide a more comprehensive view of the national risk.
\end{abstract}

Keywords Existing buildings $\cdot$ Earthquake $\cdot$ Risk assessment $\cdot$ Seismic vulnerability · Fragility curves

\section{Introduction}

The National Risk Assessment released by the Italian Civil Protection Department (DPC) in 2018 (DPC 2018) points out that earthquakes caused about 160,000 fatalities in the last two centuries. In the last 50 years, fatalities were about 5000, while discounted value of economic losses amounts to over 200 billion Euro. These dramatic effects mainly depend

Angelo Masi

angelo.masi@unibas.it

1 School of Engineering, University of Basilicata, Potenza, Italy

2 Department of Civil, Chemical and Environmental Engineering, University of Genoa, Genova, Italy

3 Department of Civil Protection, Presidency of the Council of Ministers, Rome, Italy 
on the high vulnerability of the existing building stock, as it was designed and realized either for gravity loads only or using inadequate seismic criteria. In fact, up to 1981 about $77 \%$ of the current residential buildings had already been constructed and only $25 \%$ of the national territory was classified and then subjected to seismic code. Besides old masonry constructions (Lagomarsino 2012; Cattari et al. 2014), also Reinforced Concrete (RC) buildings showed high vulnerability during last earthquakes, such as Irpinia 1980 (Braga et al. 1982) and, more recently, Abruzzo 2009 and Central Italy 2016 (Dolce and Goretti 2015; Masi et al. 2019).

After the first studies on the Italian seismic risk (see Dolce et al. 2020 for a review), in 2018 the DPC supported a research project involving its centres of competence such as ReLUIS (Network of University Laboratories for Earthquake Engineering) and Eucentre (European Centre for Training and Research in Earthquake Engineering), to prepare an updated version of the national seismic risk assessment (NRA) by considering the better knowledge reached so far. To this purpose, the IRMA platform (Borzi et al. 2008; 2020) released by Eucentre was purposely set up and used to analyse different vulnerability/exposure models and convoluting them (Dolce et al. 2020) with the MPS04 hazard model made by INGV (national Institute of Geophysics and Volcanology) in 2004 (Stucchi et al. 2011. Fragility curves for the building types mostly present in the Italian building stock according to the ISTAT 2011 census were obtained from different approaches, mainly empirical methods based on the Da.D.O. (Database of Observed Damage) database (Dolce et al. 2019). Da.D.O. contains damage data relevant to nine of the most damaging Italian earthquakes in the 1976-2012 period, mostly referred to masonry buildings (about 78\%, corresponding to about 250,000 buildings), while data on $\mathrm{RC}$ buildings is lower (about $8 \%$, corresponding to about 24,000 buildings). Other (i.e. steel, timber and mixed structures) or not identified types amount to about $12 \%$. The NRA provides results in terms of mean annual losses in terms of expected repair/reconstruction costs (direct economic losses), number of unusable buildings/dwellings, homeless, dead and injured (Dolce et al. 2020).

In 2019, a new research agreement between DPC and ReLUIS was subscribed for the period 2019-2021, made up of several Work Packages (WPs) dealing with the earthquake engineering topics most relevant for the Italian Civil Protection. Specifically, WP4 "Seismic Risk Maps-MARS" is in logical progression with the 2018 risk assessment. MARS comprises 11 Tasks, coordinated by leading Italian researchers in each specific field, listed below:

TASK 4.1-Exposure: inventory, regionalization, classification

TASK 4.2-Seismic Input: intensity measures, microzonation and shake maps

TASK 4.3-Vulnerability: models and fragility curves of residential buildings

TASK 4.4-Risk: evaluation of consequences and economic losses

TASK 4.5-Damage Scenarios: vulnerability models' validation and criteria for their combination

TASK 4.6-Prevention Strategies: risk comparison analyses at national scale

TASK 4.7-Schools: models and fragility curves of school buildings and other strategic buildings

TASK 4.8-Churches: models and fragility curves of churches

TASK 4.9-Bridges: models and fragility curves of bridges

TASK 4.10-Interaction with Eucentre for updated/new risk maps' platforms

TASK 4.11—Updated Risk Maps

The main goals of MARS are: 
- To collect, analyse and upgrade vulnerability models for both residential building stock and for single buildings/infrastructures (schools, churches, bridges);

- To collect, analyse and upgrade loss models to estimate direct economic losses, unusable buildings, and casualties;

- To release, on the base of updated exposure, hazard and vulnerability models, new seismic risk maps for both as-built and strengthened buildings, useful to plan mitigation strategies.

Within the above activities, a critical review and comparison of the different methods that were used to derive the fragility curves adopted in the 2018 study needs to be firstly carried out, in order to better understand the inherent capability and reliability to assess building vulnerability (da Porto et al. 2020). Specifically, as a consequence of the limited amount of observational damage data, additional fragility functions for RC building types need to be derived in order to complement the results of the previous study. To this purpose, analytical approaches involving some RC types not considered (e.g. high-rise and strengthened buildings) or for which damage data is poor (e.g. for higher damage levels) can be adopted, also in the framework of a hybrid approach (Dolce 1996; Kappos et al. 2006; Calvi et al. 2006).

Building type selection will take advantage from a special work-package of the DPCReLUIS project, i.e. "WP2-Cartis", which aims at collecting building data according to a more risk-oriented approach, able to better highlight local/regional distinctive structural features, not included in the ISTAT census data (Zuccaro et al. 2015). Further, a properly ground motions' selection representative of the Italian seismic hazard, also accounting for the role of amplification effects, will be carried out in order to evaluate structural response and its record-to-record variability by means of time history non-linear dynamic analyses.

In the present paper some of the most relevant aspects that are being introduced in the development of the new Italian risk maps are described and analysed. A special emphasis is devoted to: (1) the update of the vulnerability model implemented in the upgraded version of the IRMA platform, (2) the derivation of fragility curves through analytical methods, especially for RC buildings, (3) the seismic risk assessment of specific building types, such as school buildings and churches.

\section{The MARS vulnerability model}

In 2018, the seismic risk scenario for the National Risk Assessment (DPC 2018) was evaluated with the platform IRMA (Borzi et al. 2020), by combining the ones obtained by using different vulnerability models (Rosti et al. 2020a, b; Lagomarsino et al. 2021; Donà et al. 2020; Zuccaro et al. 2020; Borzi et al. 2020) and assigning to them the same weight (Dolce et al. 2020).

The vulnerability of the residential building stock is defined in the platform IRMA (Borzi et al. 2020) as follows:

- 5 damage levels $(\mathrm{Dk}, \mathrm{k}=1, \ldots 0.5)$ are considered, in accordance with the European Macroseismic Scale (EMS) (Grunthal 1998);

- Fragility curves of the 5 damage levels are introduced for 5 vulnerability classes, named $\mathrm{A} / \mathrm{B} / \mathrm{C} 1 / \mathrm{C} 2 / \mathrm{D}$, characterised by decreasing vulnerability; 
- The inventory of the residential building stock, at national level, is based on the ISTAT census (ISTAT 2011), which contains information on the structural material, the construction age and the number of stories, aggregated at municipality level;

- The vulnerability of each ISTAT type (defined by a taxonomy that combines the structural material, the construction age and the number of stories) is assigned by a linear combination of fragility curves assigned to the above-mentioned vulnerability classes (this means that each ISTAT type is defined as being made of percentages of pre-defined classes).

The vulnerability classes are not directly associated to a specific building type but collect buildings characterized by the same relation between the seismic intensity and the damage. It is worth noting that in the literature these vulnerability classes have been used, within the Damage Probability Matrix simplified approach (e.g. Braga et al. 1982), by associating specific building types to each one:

- Class A: traditional irregular masonry buildings, with low quality structural details;

- Class B: traditional regular masonry buildings, with good quality structural details;

- Class C1: solid brick or modern masonry buildings with rigid horizontal diaphragms;

- Class C2: reinforced concrete building without earthquake resistant design (designed for gravitational loads);

- Class D: reinforced concrete building with earthquake resistant design.

However, it is worth noting the ISTAT inventory allows a pretty accurate classification and it would be too rough the direct association of each ISTAT type to one of the 5 considered classes. Therefore, the 5 sets of fragility curves defined for the vulnerability classes represent a vulnerability metrics, useful to associate to each ISTAT type a specific set of fragility curves that represent the possible different behaviour of the same type. Indeed, the IRMA platform evaluates the damage for each ISTAT type by combining with the introduced percentages the damage of the 5 reference vulnerability classes. This approach is conceptually coherent with the EMS, because it assumes that in the specific building type there are structures belonging to different vulnerability classes and vice versa (for further details see Dolce et al. 2020).

The set of lognormal fragility curves of one vulnerability class is defined by the median values of the Peak Ground Acceleration (PGA) relevant to the 5 damage levels, together with the correspondent values of the statistical dispersion; obviously the former increase passing from a vulnerability class to the following, less vulnerable. However, the seismic performance is determined also by the relative distance between damage levels, which increases in the case of ductile structures (for example, in a ductile structure, given the PGA that causes damage D2, it should be increased more in order to reach damage D3). This is why class $\mathrm{C}$ is usually divided into classes $\mathrm{C} 1$ and $\mathrm{C} 2$ : modern masonry buildings and gravitational RC ones have, on average, a similar vulnerability but the distribution of damage levels is different.

For the seismic risk assessment released in 2018, each research group has defined independently 5 sets of fragility curves for the vulnerability classes adopted by the platform IRMA: this choice makes the comparison between different models very difficult, unless it is made directly in terms of damage and loss scenarios.

One of the aims of the WP4-MARS of the DPC-ReLUIS project is to develop an advanced vulnerability consensus model to update the seismic risk scenario for the NRA, 
in order to improve both the confidence on the results and the clearness of the whole model at national scale. The distinctive and original features are the following:

- Univocal definition of the vulnerability, through sets of fragility curves associated to the six EMS vulnerability classes, from A to F; therefore, the research groups assign the vulnerability to each ISTAT building type through a linear combination of fragility curves associated to the EMS classes (the coefficients are percentages whose sum should be equal to one); it is worth noting that with this approach the comparison between vulnerability models is straightforward, just in terms of the percentages assigned to the EMS classes;

- Derivation of a unique and shared vulnerability model, by a combination of the weights proposed by research groups for each ISTAT type, without the need of calculating many damage scenarios to be combined ex-post; this approach makes the validation of the models, at the level of each single ISTAT type, easy; moreover, in this way it is very easy to implement the contribution of research groups that develop models only for some of the ISTAT types;

- Evaluation of the vulnerability at sub-national scale (by considering different subnational areas: administrative regions, population and altimetric areas): the ISTAT building inventory, available at national scale for the residential building stock, does not include specific structural information (masonry features, horizontal diaphragms, earthquake resistant system in the case of RC buildings, etc.), which significantly influences the vulnerability; these data, at least for significant statistical samples, are available from a national on-site survey (Zuccaro et al. 2015) that highlights the structural features of residential buildings in the different areas of Italy; the platform IRMA allows the different territorial areas to be analyzed separately, by applying each time the specific vulnerability models, and then merging the results in order to get the national risk maps;

- Seismic risk assessment of some types of special buildings (portfolio analysis), thanks to the availability of structural information on any single georeferenced building (school buildings, churches): to this end, specific platforms have been developed (IRMA school buildings; IRMA churches), which adopt the same vulnerability metrics based on the EMS vulnerability classes.

\subsection{Formulation of the MARS model: fragility curves of the EMS98 vulnerability classes}

According to the above-mentioned aims, the WP4-MARS has developed a vulnerability model that allows an effective and accurate definition of fragility curves do be defined for the ISTAT building types. It has been implemented in the updated version of the platform, named IRMA 2.0, which allows different research groups to propose their vulnerability models and to contribute to define harmonized fragility curves. The general framework is still based on a set of vulnerability classes, but in order to consider also modern buildings with advanced earthquake resistant design, reference is made to the 6 EMS classes, from A to F; moreover, the possibility of either a brittle or a ductile behavior is explicitly considered.

The set of 5 fragility curves, associated to one EMS class, is defined by the following parameters: 
- The median value $\mathrm{PGA}_{\mathrm{D} 2}$ of the damage level D2, assumed as reference for the EMS class because it is representative of a moderate damage, with slight structural damage (close to the reaching of the maximum shear strength);

- The ratios $\mathrm{PGA}_{\mathrm{Dk}} / \mathrm{PGA}_{\mathrm{D} 2}$ related to the median values of PGA for the other damage levels Dk $(\mathrm{k}=1,3,4,5)$, which are related to the seismic performance in terms of ductility (or, more precisely, in terms of behavior factor, for the higher damage levels, while for the damage level D1 is related to the overstrength ratio in masonry buildings and to the damage of infill and partition walls in RC buildings);

- The dispersion $\beta_{\mathrm{Dk}}$ associated to the damage levels, which should meet certain conditions to avoid the intersection of fragility curves within the interval of numerical integration of the risk convolution.

Each vulnerability class is then identified by the value PGA $_{\mathrm{D} 2}$ (Table 1). These values have been obtained from those assigned by the different research groups for the NRA in 2018, just to have an agreed reference, but it is worth noting that these classes represent a vulnerability metrics for the assignment of the set of fragility curves to any ISTAT type, through a linear combination. According to EMS, the difference between a vulnerability class and the following is that an increment of one degree of the macroseismic intensity is needed to have the same damage level. The correlation laws between macroseismic intensity and PGA are characterized by a mathematical relation in which to the increment of one intensity degree corresponds a constant multiplication factor of PGA; many correlations are available in the literature, from which on average this factor may be assumed equal to 1.7. This value has been used for the definition of EMS vulnerability classes (Table 1).

Regarding the seismic performance of the ISTAT types in terms of ductility, the fragility curves proposed by the different research groups for NRA-2018, through empirical or mechanical based approaches, have highlighted some distinctive features:

- Masonry buildings: the more ancient types are more vulnerable than modern masonry buildings, because they suffer slight or moderate damage for lower values of PGA; however, the former ones result more ductile, i.e. the fragility curves are less closed together than in the case of modern masonry buildings, characterized by higher strength and lower ductility;

- RC buildings: those built before 1980, in particular when designed only for gravity loads, have a limited ductility, while the ones designed with modern codes are more ductile.

Differences in terms of ductility are expected even in the case of buildings before and after seismic retrofitting interventions; this information is relevant for planning mitigation and assess their effectiveness. If ancient masonry buildings without effective connections are considered, they are expected to be very vulnerable and brittle, because of the high vulnerability to local out-of-plane mechanisms (i.e., damage levels D4 and D5 are attained with PGA values only slightly larger than the one producing a moderate damage). The improvement of connections (e.g. with steel tie rods) reduces the

Table 1 Median values of PGA for the damage level D2 that define the EMS vulnerability classes

\begin{tabular}{lllllll}
\hline Vulnerability class & A & B & C & D & E & F \\
\hline PGA $_{\mathrm{D} 2}[\mathrm{~g}]$ & 0.11 & 0.19 & 0.32 & 0.54 & 0.92 & 1.57 \\
\hline
\end{tabular}


vulnerability to local mechanisms, but does not change significantly the damageability: then, according to the MARS model, the building would belong to the same EMS class but with increased ductility. Following the strengthening of masonry walls, the maximum base shear of the building increases and, therefore, the value of $\mathrm{PGA}_{\mathrm{D} 2}$ : the building would pass to a higher EMS class, without changing the ductility. Finally, even the ductility would be incremented if also in-plane strengthening of horizontal diaphragms, with connection to the masonry walls, is adopted.

The comparative analysis of fragility curves used in the 2018 risk assessment has shown (e.g. Rosti et al. 2020a, b; Lagomarsino et al. 2021) that the distance between the damage levels is well represented by the following law:

$$
P G A_{D k}=P G A_{D 2} e^{\alpha(k-2)} k=1, \ldots, 5
$$

where $\alpha$ is a free parameter that ranges between 0.36 and 0.66 , moving from the maximum brittle to ductile behavior. Table 2 shows the values associated to the limit cases: it is worth noting that in the case of maximum brittleness the damage level D4 (representative of near collapse) is attained with a double PGA compared to that of moderate damage (D2), while in the case of maximum ductility this factor rises to 3.8. Therefore, the set of fragility curves of a building type may be univocally defined by two parameters only: $\mathrm{PGA}_{\mathrm{D} 2}$ (ranging between the values of Class $\mathrm{A}$ and $\mathrm{F}$ in Table 1 ) and $\alpha$ (ranging between the limit values 0.36 and 0.66 ).

Then, the MARS vulnerability model is based on the definition, for each EMS class, of two sets of fragility curves, named brittle and ductile, characterized by the same value $\mathrm{PGA}_{\mathrm{D} 2}$ (Table 1) but by a different distance between damage levels. The vulnerability to damage level D2, named moderate in EMS and representative of the building shear strength in the pseudo-elastic phase, is then what characterizes each EMS class.

The assignment of the set of fragility curves to each ISTAT type, derived through an empirical or mechanical-based approach, may be done as a linear combination of 4 sets of fragility curves, properly selected among the 6 EMS classes, each one available in the double option of brittle and ductile behavior. The procedure is based on the following steps:

1. Identification of the two consecutive EMS classes $C_{i}$ and $C_{i+1}\left(C_{1} \equiv A, C_{6} \equiv F\right)$, within which the behavior of the ISTAT type is included, and calculation of the corresponding weights:

$$
w_{i}=\frac{P G A_{D 2, C_{i+1}}-P G A_{D 2}}{P G A_{D 2, C_{i+1}}-P G A_{D 2, C_{i}}} \quad w_{i+1}=1-w_{i}
$$

2. Identification of the parameter $\alpha$ that better reproduces the $\mathrm{PGA}_{\mathrm{Dk}}$ of the different damage levels; this parameter may be obtained by a minimum least squares regression through the following relation:

Table 2 Median values of PGA for the attainment of different damage levels with respect to D2, in the conditions of both brittleness and ductility

\begin{tabular}{lllllll}
\hline & & \multicolumn{6}{l}{$\mathrm{PGA}_{\mathrm{Dk}} / \mathrm{PGA}_{\mathrm{D} 2}$} \\
\cline { 3 - 7 } Vulnerability Class & $\alpha$ & $\mathrm{D} 1$ & $\mathrm{D} 2$ & $\mathrm{D} 3$ & $\mathrm{D} 4$ & $\mathrm{D} 5$ \\
\hline brittle & 0.36 & 0.70 & 1 & 1.43 & 2.05 & 2.95 \\
ductile & 0.66 & 0.52 & 1 & 1.94 & 3.74 & 7.24 \\
\hline
\end{tabular}




$$
\alpha=\frac{\sum_{k=1}^{5}(k-2) \log \left(P G A_{D k} / P G A_{D 2}\right)}{\sum_{k=1}^{5}(k-2)^{2}}(0.36 \leq \alpha \leq 0.66)
$$

3. Identification of the weights to be assigned to the brittle and ductile classes to obtain the performance of the ISTAT type, given the parameter $\alpha$ :

$$
w_{b}=\frac{0.66-\alpha}{0.3} \quad w_{d}=1-w_{b}
$$

4. Evaluation of the final weights to be assigned to the 2 EMS classes, each one subdivided into 2 sub-classes $\left(C_{i, b}, C_{i, d}, C_{i+1, b}\right.$ and $\left.C_{i+1, d}\right)$ needed to reproduce the complete set of fragility curves of the ISTAT type:

$$
w_{i, b}=w_{i} w_{b} \quad w_{i, d}=w_{i} w_{d} \quad w_{i+1, b}=w_{i+1} w_{b} \quad w_{i+1, d}=w_{i+1} w_{d}
$$

Finally, regarding the dispersion $\beta$ of the lognormal fragility curves, it is worth considering that it is the result of different contributions, which may be usually assumed as statistically independent and then combinable with the SRSS rule. If fragility curves are referred to a single building, the dispersion is mainly due to the record-to-record variability, as uncertainties on the material properties, the structural features and the thresholds to define the damage levels are less relevant. However, in a seismic risk analysis at national scales, with poor information for the building classification (taxonomy), the fragility curves should be representative of wide building types, which includes many architectural and structural configurations with a different behavior; moreover, the definition of damage levels, in particular from observational approaches, is a difficult task.

The fragility curves adopted by the 2018 risk assessment (Dolce et al. 2020) have values of the dispersion between 0.5 and 0.8 ; usually, greater values are associated to the more ductile sets of fragility curves. The derivation of fragility curves, both from empirical damage data or mechanical-based models, leads to values of the dispersion that are different for any damage level. This implies the intersection of fragility curves, which is theoretically inconsistent, because the probability to exceed a given damage level cannot be higher than the probability to exceed a lower damage level. The intersection occurs for low values of the PGA when the dispersion of a given damage level is higher than that of a lower level, or for high values of PGA in the opposite case. However, as the platform IRMA evaluates numerically the convolution integral of seismic risk (Cornell 1968) in the interval of values $\mathrm{PGA}_{\min }<\mathrm{PGA}<\mathrm{PGA}_{\max }$, it is sufficient that the intersections between fragility curves are out of this interval. After simple mathematical steps it is possible to derive that this compatibility conditions is guaranteed by the following relation:

$$
\beta_{D k} \frac{\log \left(P G A_{\max }\right)-\log \left(P G A_{D j}\right)}{\log \left(P G A_{\max }\right)-\log \left(P G A_{D k}\right)}<\beta_{D j}<\beta_{D k} \frac{\log \left(P G A_{\min }\right)-\log \left(P G A_{D j}\right)}{\log \left(P G A_{\min }\right)-\log \left(P G A_{D k}\right)} \text { with } j>k
$$

Figure 1 shows the fragility curves of damage level D2 for the 6 EMS classes (the dispersion has been assumed constant and equal to 0.65). It is worth noting that passing from a specific EMS class to the following one, the PGA needed to induce the same probability of attainment of D2 increases by a constant factor (about 1.7, from Table 1): this is compatible with the definition in EMS, where the performance of vulnerability classes is associated to an increase of one macroseismic intensity degree, and with usual correlations between intensity and PGA (in logarithmic form). Moreover, it is evident that vulnerability classes collect buildings with different performance, because, for example, for $\mathrm{PGA}=0.19 \mathrm{~g}$ (median value $\mathrm{PGA}_{\mathrm{D} 2}$ of class $\mathrm{B}-50 \%$ of buildings of class B suffer D2 or more), around $20 \%$ of buildings of class C presents the same damage 
Fig. 1 Fragility curves of the damage level D2 for the six EMS vulnerability classes $(\beta=0.65)$

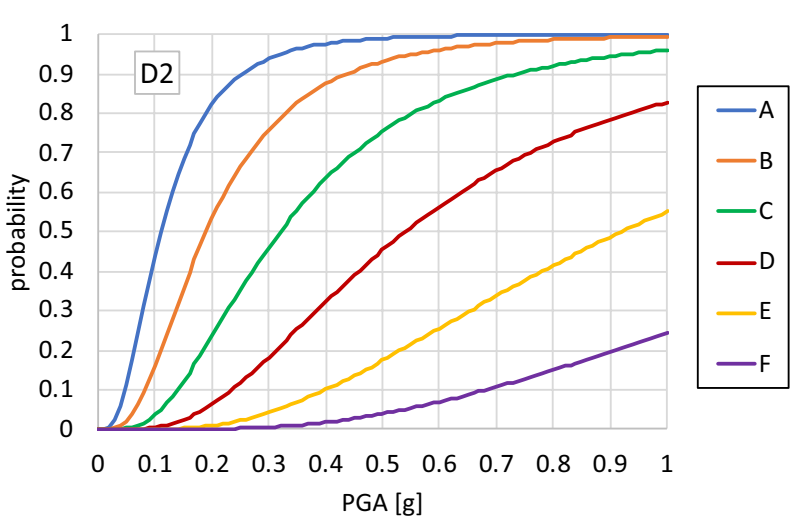

and even $80 \%$ of buildings of class A have a lower damage level: this is an effect of the adopted dispersion ( $\beta=0.65$, in the figure). Figure 2 shows, for EMS class $B$, the influence on the set of fragility curves for the 5 damage levels, due to: (a) brittle and ductile behaviour (Table 2); (b) dispersion $(\beta=0.5$ and $\beta=0.8$, assuming a medium ductility behaviour $(\alpha=0.51)$. It is worth noting that the red curves, referred to damage level D2, are coincident in Fig. 2a, while in Fig. 2b have only the same median PGA $\left(\mathrm{PGA}_{\mathrm{D} 2}=0.19 \mathrm{~g}\right)$ but the different values of the dispersion $\beta$ determine a steeper or lower slope (in the latter case, due to the higher dispersion, increasing or reducing the PGA the global performance of the EMS class changes to a less significant extent). Moreover, Fig. 2a shows that in the case of brittle behaviour (dashed lines) fragility curves are closer together, while in the case of ductile behaviour (dotted lines) the distance between the damage levels is bigger (according to Table 2). Finally, Fig. $2 b$ shows that the dispersion does not influence the median values of the five damage levels $\mathrm{PGA}_{\mathrm{Dk}}$.

The framework of the new platform IRMA 2.0 is compatible with the MARS vulnerability model, and allows to implement the fragility of a building type with two

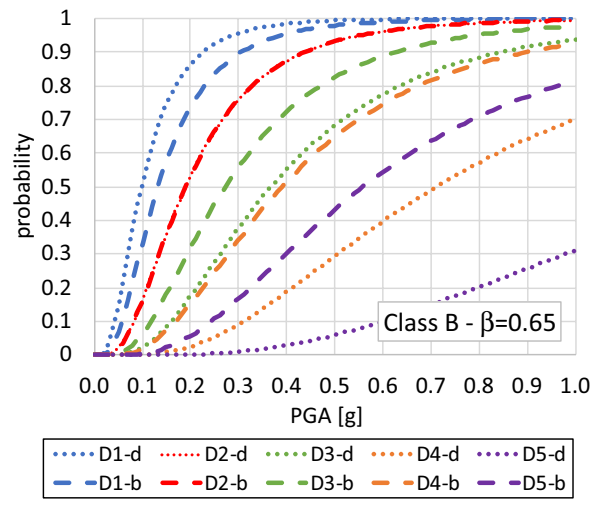

(a)

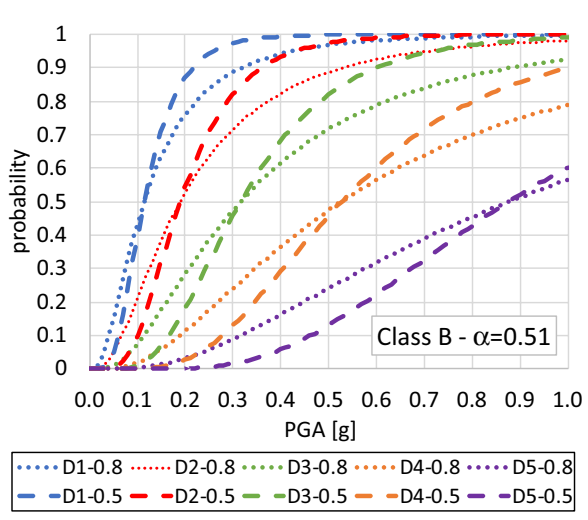

(b)

Fig. 2 Fragility curves of Class B: a for the brittle $(\alpha=0.36)$ and ductile $(\alpha=0.66)$ behaviour $(\beta=0.65)$; b influence of the dispersion ( $\beta=0.5$ or 0.8$)$, for a medium ductility behaviour $(\alpha=0.51)$ 
alternative approaches, depending on the information available and the database architecture of considered buildings:

- Residential building stock (ISTAT inventory, aggregated at municipality scale): for each ISTAT type (defined by structural material, construction age, and number of stories) the two EMS classes between which the actual behavior is found are identified, and the corresponding percentages are calculated (weights provided by Eq. 5), for both the version brittle and ductile; the seismic scenario is evaluated through a combination of damage and consequences obtained for the EMS vulnerability classes, by using the above-mentioned percentages;

- School buildings portfolio (classification of each building through a specific taxonomy): the inventory of school buildings contains structural information (seismic resistant system, horizontal diaphragms, etc.) that allows sub-types to be defined, starting from ISTAT types, and to each one a set of fragility curves is associated; the vulnerability of each sub-type is defined in terms of percentages of the EMS classes, analogously to the case of ISTAT types for the residential building stock, but in this case a specific set of lognormal fragility curves are defined by evaluating the parameters (median values of PGA and dispersions for the 5 damage levels) as follows:

$$
\begin{gathered}
P G A_{D k}=w_{i, b} P G A_{D k, C_{i, b}}+w_{i, d} P G A_{D k, C_{i, d}}+w_{i+1, b} P G A_{D k, C_{i+1, b}}+w_{i+1, d} P G A_{D k, C_{i+1, d}} \\
\beta_{D k}=w_{i, b} \beta_{D k, C_{i, b}}+w_{i, d} \beta_{D k, C_{i, d}}+w_{i+1, b} \beta_{D k, C_{i+1, b}}+w_{i+1, d} \beta_{D k, C_{i+1, d}}
\end{gathered}
$$

Figure 3 shows, as an example, the fragility curves of a building typology characterized by the following parameters: $\mathrm{w}_{\mathrm{B}}=0.25, \mathrm{w}_{\mathrm{C}}=0.75, \mathrm{w}_{\mathrm{b}}=0.5, \mathrm{w}_{\mathrm{d}}=0.5, \beta_{\mathrm{b}}=0.5, \beta_{\mathrm{d}}=0.8$. Curves are related to damage level D3. The blue curve is a weighted sum of the fragility curves of the classes B and C: this approach is used in the platform IRMA 2.0 for the ISTAT typologies of the residential building stock. The red curve is a lognormal fragility curve with the following parameters PGA $\mathrm{D}_{3}=0.455 \mathrm{~g}, \beta=0.65$ (obtained by Eqs. 7 and 8 ): this approach is used for the typologies of building schools, as defined in the platform IRMA 2.0. It is worth noting that in the former case (blue curve) the resulting dispersion is a bit higher because it includes the dispersion due to the combination of curves with different median values; in order to overcome

Fig. 3 Fragility curves implemented in the platform IRMA 2.0 for the ISTAT residential building stocks and the inventory of school buildings

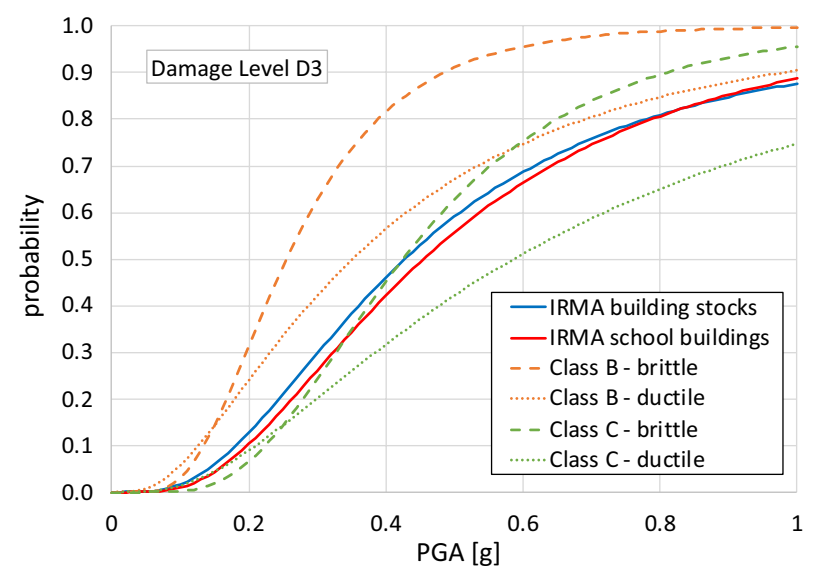


this problem, the dispersion of the EMS Classes should be slightly reduced, in particular for the higher damage levels.

\subsection{Implementation of fragility curves for building stock types}

The seismic risk scenario at national scale is evaluated by splitting the residential building stock into building types and considering specific fragility curves, as implemented in IRMA 2.0. Information on the building stock, aggregated at municipality scale, are fully available all over Italy from the ISTAT census made in 2011, which includes three levels of information (taxonomy):

- Structural material (2 types): M (masonry) or RC (reinforced concrete);

- Construction age (9 periods): A1 (<1919), A2 (1919-1945), A3 (1946-1960), A4 (1961-1970), A5 (1971-1980), A6 (1981-1990), A7 (1991-2000), A8 (2001-2005), A9 (>2005);

- Number of stories (4 different classes of building height): L1, L2, L3 and L4+( $\geq 4$ stories).

Therefore, 72 different ISTAT types may be identified. In addition, it is evident that the level of seismic design influences the vulnerability. This matter is taken into account by considering the evolution of the seismic classification along the years in each municipality; in particular, the reduction of vulnerability is assumed significant only in moderate to high seismic hazard areas. In the case of reinforced concrete buildings, starting from 1946, vulnerability is assumed different whether the municipality is classified (A3S) or not (A3) as moderate to high seismic hazard; for masonry buildings the seismic classification is assumed as relevant only after 1981. Therefore, 44 further ISTAT types should be considered. At the end, 116 ISTAT types are considered, which are identified by tags related to the above-mentioned taxonomy (for example: M/A1/L3, RC/A5S/L4+).

The assignment of fragility curves to each ISTAT type is made by using fragility curves of EMS98 Classes, according to the procedure of Eqs. (2-5) in §2.1: weights are assigned to EMS98 Classes, combining both brittle and ductile behavior, and their summation should be equal to one (Table 3 ); it is expected that only $2+2$ classes are considered for each ISTAT type.

For each ISTAT type, the set of 5 fragility curves may be derived by the research groups by any method (empirical, mechanical, hybrid) and converted through the MARS vulnerability metric (Table 3) in order to be implemented in the platform IRMA 2.0. The building typology/vulnerability matrices derived by different research groups may be easily compared and integrated, to end up with the MARS building typology/vulnerability matrix, useful for the calculation of the seismic risk scenario. The integration of available models should consider the confidence of each one (by possibly adopting different weights in the combination), on the basis of: validation with observed data, representativeness of the model with respect to

Table 3 Example of assignment of the vulnerability to two ISTAT types by the MARS model

\begin{tabular}{lllllllllllll}
\hline ISTAT type & $w_{\mathrm{A}, \mathrm{b}}$ & $w_{\mathrm{A}, \mathrm{d}}$ & $w_{\mathrm{B}, \mathrm{b}}$ & $w_{\mathrm{B}, \mathrm{d}}$ & $w_{\mathrm{C}, \mathrm{b}}$ & $w_{\mathrm{C}, \mathrm{d}}$ & $w_{\mathrm{D}, \mathrm{b}}$ & $w_{\mathrm{D}, \mathrm{d}}$ & $w_{\mathrm{E}, \mathrm{b}}$ & $w_{\mathrm{E}, \mathrm{d}}$ & $w_{\mathrm{F}, \mathrm{b}}$ & $w_{\mathrm{F}, \mathrm{d}}$ \\
\hline M/A1/L2 & 0.21 & 0.49 & 0.09 & 0.21 & 0 & 0 & 0 & 0 & 0 & 0 & 0 & 0 \\
RC/A5S/L4+ & 0 & 0 & 0 & 0 & 0.28 & 0.12 & 0.42 & 0.18 & 0 & 0 & 0 & 0 \\
\hline
\end{tabular}


building variability in the considered building type. For each ISTAT type, the final result may be a combination of two EMS vulnerability classes $(2+2$ classes, considering for each class a combination of the brittle and the ductile one), when all models confirm a similar estimate, or may involve more than two EMS classes, In the latter case, the resulting fragility curves, simply obtained by a weighted average (for each PGA value), will have median values of $\mathrm{PGA}_{\mathrm{Dk}}$ determined by the majority of the groups but a higher dispersion; this is not necessarily due to a lack of agreement among research groups on the seismic behavior of the building type, but may represent the actual inter-building dispersion of the considered ISTAT type.

This resulting vulnerability assessment is fully coherent with the vulnerability table in the EMS 98 (Fig. 4), where for each building type there is a most likely vulnerability class, but also less probable classes and exceptional cases. It is worth noting that ISTAT types are well defined in terms of age of construction and number of stories, but there is no information on masonry type (for masonry) or on the resisting system (frame/walls for RC); therefore, a large dispersion is expected.

This approach allows for taking into account the contribution of research groups working only on specific building types, because also an incomplete building typology/vulnerability matrix may be integrated in the model. This was not possible in the NRA 2018, when the combination of the contributions was made directly on the seismic risk map, because the IRMA platform requires a complete characterization of the vulnerability.

The building typology/vulnerability matrix gives a clear picture of the seismic behavior of the residential building stock. It will be very useful for a validation of the single models proposed. Indeed, some qualitative trends are expected: (1) vulnerability of masonry buildings is higher than that of RC ones; (2) vulnerability increases with the age of construction; (3) vulnerability increases with the number of stories (especially in case of masonry buildings); (4) RC buildings without earthquake resistant design are brittle while ductility increases with modern codes. A systematic comparison between fragility curves derived from observed damage or mechanical models is needed, with the aim of ending up with a cross-calibration and combination of results. As a matter of fact, results obtained by mechanical models often underestimate the seismic capacity, due to cautionary modelling hypotheses and parameters, but observed damage data are often incomplete and affected by errors in the damage survey and the seismic intensity estimation.

\subsection{Consideration of regional vulnerability features in the national risk assessment}

ISTAT types do not consider structural features that are relevant for the evaluation of the seismic vulnerability. This vulnerability model, when used for the seismic risk assessment

\begin{tabular}{|l|l|l|l|l|l|l|}
\hline \multirow{2}{*}{ Masonry type } & \multicolumn{5}{|c|}{ Vulnerability class } \\
\hline & A & B & C & D & E & F \\
\hline rubble stone, fieldstone & & & & & & \\
\hline adobe (earth brick) & & & & & & \\
\hline simple/regular stone & & & & & & \\
\hline massive stone & & & & & & \\
\hline unreinforced/RC floors & & & & & & \\
\hline reinforced or confined & & & & & & \\
\hline
\end{tabular}

\begin{tabular}{|l|l|l|l|l|l|l|}
\hline \multirow{2}{*}{ RC type } & \multicolumn{6}{|c|}{ Vulnerability class } \\
\hline & A & B & C & D & E & F \\
\hline frame without ERD & & & & & & \\
\hline frame / moderate ERD & & & & & & \\
\hline frame / high level ERD & & & & & & \\
\hline walls without ERD & & & & & & \\
\hline walls / moderate ERD & & & & & & \\
\hline walls / high level ERD & & & & & & \\
\hline
\end{tabular}

most likely vulnerability class probable range less probable, exceptional cases

Fig. 4 Classification of buildings into vulnerability classes by the EMS ( adapted from Grunthal 1998) 
at national scale, should be on average representative of different building types that are present in all the regions and areas of Italy. However, significant differences may be observed that should be taken into account.

The WP2-CARTIS of the DPC-ReLUIS Project (Zuccaro et al. 2015) has made and is still improving a widespread survey of the structural features of masonry and RC buildings all over Italy, by assuming a specific taxonomy:

- Masonry: A1-rubble stone masonry; A2-simple stone masonry; B-regular masonry; $\mathrm{C} 1$-squared blocks masonry (tuff, limestone); $\mathrm{C} 2$ - solid bricks masonry; D1 - brittle hollow blocks (high percentage of holes); D2-modern blocks (with low percentage of holes);

- Horizontal diaphragms (in masonry buildings): f-flexible (timber floors); s-stiff (mixed steel and brick floors, timber floors with double timber plank or reinforcing slab); r-rigid (RC floor); v-masonry vaults;

- RC buildings: A-walls or cores, connected to RC frames; B-RC frames with stiff and resistant infills; $\mathrm{C}-\mathrm{RC}$ frames with high beams and weak infills; $\mathrm{D}-\mathrm{RC}$ frames with high perimetric beams and weak infills; $\mathrm{E}-\mathrm{RC}$ frames with flat beams.

This taxonomy allows for the identification of ISTAT sub-types, in which the tags are added to the taxonomy of ISTAT types (Table 3).

In the case of masonry buildings, tags related to the characteristics of masonry blocks and horizontal diaphragms are added (e.g., M/A1/L2/B/v). Indeed, not all possible combinations of the last two tags are relevant, as well as some types are not present in all ages. Table 4 shows a possible simplified definition of sub-types (in addition, D1 is present in low seismicity areas, while D2 are used in areas of moderate to high seismic hazard).

Regarding RC buildings, horizontal diaphragms may be considered always rigid, even if before 1960 the lightened floors sometimes do not have a continuous thin slab over the hollow clay blocks; however, this structural detail is not available and this source of vulnerability is considered within the age class. It is worth noting that $\mathrm{RC}$ walls or cores are used in high rise buildings, therefore for $\mathrm{L} 4+$ and, at least, L3. Regarding the age of construction, a progressive transition between type B to E may be observed, even if without a clear time-related delimitation.

The CARTIS project provides statistical information of all these sub-types, considering different subdivision of Italy in sub-areas:

- Administrative Regions: they are 20, but there is no information on 3 of them (Trentino Alto Adige, Valle d'Aosta and Sardinia);

Table 4 Relevant ISTAT sub-types for masonry in terms of combination among construction age, masonry type and horizontal diaphragms

\begin{tabular}{|l|c|c|c|c|c|c|c|}
\hline floors masonry & $\mathrm{A} 1$ & $\mathrm{~A} 2$ & $\mathrm{~B}$ & $\mathrm{C} 1$ & $\mathrm{C} 2$ & $\mathrm{D} 1$ & $\mathrm{D} 2$ \\
\hline masonry vaults & $\mathrm{A} 1 / \mathrm{v}$ & $\mathrm{A} 2 / \mathrm{v}$ & $\mathrm{B} / \mathrm{v}$ & $\mathrm{C} 1 / \mathrm{v}$ & $\mathrm{C} 2 / \mathrm{v}$ & - & - \\
\hline flexible & $\mathrm{A} 1 / \mathrm{f}$ & $\mathrm{A} 2 / \mathrm{f}$ & $\mathrm{B} / \mathrm{f}$ & $\mathrm{C} 1 / \mathrm{f}$ & $\mathrm{C} 2 / \mathrm{f}$ & - & - \\
\hline stiff & $\mathrm{A} 1 / \mathrm{s}$ & $\mathrm{A} 2 / \mathrm{s}$ & $\mathrm{B} / \mathrm{s}$ & $\mathrm{C} 1 / \mathrm{s}$ & $\mathrm{C} 2 / \mathrm{s}$ & $\mathrm{D} 1 / \mathrm{s}$ & $\mathrm{D} 2 / \mathrm{s}$ \\
\hline rigid & $\mathrm{A} 1 / \mathrm{r}$ & $\mathrm{A} 2 / \mathrm{r}$ & $\mathrm{B} / \mathrm{r}$ & $\mathrm{C} 1 / \mathrm{r}$ & $\mathrm{C} 2 / \mathrm{r}$ & $\mathrm{D} 1 / \mathrm{r}$ & $\mathrm{D} 2 / \mathrm{r}$ \\
\hline \hline
\end{tabular}


- Population class: municipalities are subdivided into 6 classes in terms of the number of inhabitants: P1 (> 50.000), P2 (10.000-50.000), P3 (5.000-10.000), P4 (2.000-5.000), P5 (500-2000), P6 (<500);

- Altimetric class: 5 different conditions are considered: A1-flat areas, A2 - coastal hill, A3 - hilly areas, A4 — coastal mountain, A5—mountain area.

The relevance of these three territorial ambits is different and complementary. For example, ancient masonry buildings were made by the material available on-site: solid brick masonry is the most widespread in the Po Valley, while stone masonry is found in the mountain areas. Therefore, the majority of buildings in Emilia-Romagna Region are in solid brick masonry, because most of the territory is flat, but on the mountains stone masonry is present. It was also observed that stone masonry was adopted more frequently in small towns, while in big cities brick masonry is prevalent, even in the mountain areas. Regarding the number of stories of $\mathrm{RC}$ buildings, the number of inhabitants in the municipality is a relevant parameter, because tall buildings are present in big cities (P1 and P2), while in small towns the number of stories is lower; ISTAT types do not distinguish buildings with a number of stories greater or equal to four, therefore different vulnerability models should be assumed for tall RC buildings as a function of population. Therefore, the subdivision of Italy into a number of territorial ambits given by the combination of these three features allows to provide a finer vulnerability definition.

The implementation of this valuable information in the MARS vulnerability model is straightforward. The ISTAT inventory is already aggregated at municipality scale; it provides, for each municipality, the overall exposure (number of buildings and flats, total surface of flats, number of inhabitants) and the percentage of each exposure parameter in all ISTAT types. Structural information from WP2-CARTIS allows to share the exposure into ISTAT sub-types, defined by relevant structural features, in the proper way in any specific sub-area. The result is a local accurate knowledge of the vulnerability of residential buildings.

Of course, it is expected that research groups develop fragility curves for ISTAT sub-types, in the same form as used for ISTAT types (Table 3), that is through weights assigned to the $6+6$ EMS classes. This set of information for all the sub-types forming one specific ISTAT type should be compatible with the weights in the corresponding row of the building typology/vulnerability matrix. This compatibility means that the weights of the ISTAT type should be obtained through a proper combination of the weights assigned to all the sub-type forming the ISTAT type; this combination should ideally refer to the distribution of sub-types at national level. Then, for each different sub-area (administrative Region, population class, altimetric class or any combination of them), the building typology/vulnerability matrix should be assembled by using the specific distribution of sub-types in any ISTAT type.

The IRMA platform allows to evaluate the seismic risk scenario by selecting in advance the sub-areas and assigning the specific building typology/vulnerability matrix. Then, all scenarios may be assembled in order to end up with the national risk assessment.

\section{Fragility curves from mechanical approaches}

A beneficial step in order to improve the previous NRA (DPC 2018) is the derivation of fragility curves through mechanical approaches, especially for RC buildings for which a smaller amount of data is available in the Da.D.O. damage database (Dolce et al. 2019). In such a way, additional data can be obtained by analysing the seismic response with respect 
to higher intensity values as well as to structural types widely present in the Italian building stock but missing in Da.D.O. Subsequently, empirical and analytical results can be properly combined in the framework of hybrid approaches (e.g. Dolce et al. 2006; Kappos et al. 2006; Calvi et al. 2006), by weighting them on the basis of the inherent limitations of the two approaches. To this purpose, in the following a brief overview of the two considered approaches is reported, also pointing out the main pros and cons.

Empirical methods (Dolce 1996; Dolce et al. 2003; Rossetto and Elnashai 2003; Rota et al. 2008; Del Gaudio et al. 2020) use data from post-earthquake damage surveys to derive fragility functions. On the one hand, these approaches take implicitly into account many aspects relevant for an effective risk assessment of the area under study (e.g., variability of both building types and earthquake characteristics). On the other hand, quality of data, and then reliability of the related fragility curves, can be affected by subjectivity in assigning a damage level to each building, as well as by lack of accuracy in the determination of the ground motion to which each building was subjected (Silva et al. 2014). Furthermore, the reliability of fragility curves is strongly influenced by the completeness of database, i.e. the number of available data related to both different building types and ground shaking levels. Specifically, due to the fact that available data mainly involves low-magnitude events with slight-moderate damage (especially in the case of RC buildings), empirical approaches could underestimate fragility for the higher seismic intensities (Rossetto et al. 2014). On the contrary, because undamaged buildings are generally not inspected in post-event usability surveys, fragility can be overestimated (Pitilakis et al. 2014), unless data on the undamaged buildings are available from other sources and properly included in the fragility analyses.

These possible limitations of empirical methodologies inherit additional caution when fragility curves derived from a specific area are used for different and/or wider areas, or to predict damage for different (higher) intensity levels and building types (Rossetto et al. 2014).

Analytical/mechanical methods (e.g. D’Ayala et al. 2015; Maio and Tsionis 2016; Lagomarsino and Cattari 2015) define a direct relationship between the structural response of a mechanical model, seismic intensity and expected damage. To this purpose, either single prototype structures selected to be representative of a class of buildings (e.g. Masi et al. 2015) or a set of randomly generated structures (e.g. Borzi et al. 2008; Del Gaudio et al. 2015), are generally considered. The reduced capability of a prototype (or a set of them) of representing a more complex building stock and the simplifications inevitably introduced by the structural modelling are the main limitations of the analytical approaches. As a consequence, also the identification of different sources of uncertainty (e.g. in capacity, demand and damage state thresholds) and their quantification can affect the reliability of analytical results (Rossetto et al. 2014). On the contrary, analytical approaches permit to simulate the seismic response of different building types, also analysing them under high intensity values, for which no or poor empirical data is generally available.

Currently, several analytical methods are available. In particular for the Mediterranean area, special projects such as RISK-UE (Mouroux and Le Brun 2006), LESSLOSS (Calvi and Pinho 2004), SYNER-G (Pitilakis et al. 2014), and GEM (D'Ayala et al. 2015) collected and developed fragility functions for different countries and built environments. Analytical fragility functions can be grouped on the basis of the adopted non-linear analysis method, that is static (e.g. Lagomarsino and Giovinazzi, 2006; Polese et al. 2008) or dynamic (e.g. Jalayer and Cornell, 2009; Masi et al. 2015). As a consequence of their inherent accuracy in seismic modelling along with unavoidable simplified assumptions, differences between static and dynamic methods are generally experienced in terms of seismic 
response and computing time demand (Silva et al. 2014). However, despite its greater computational effort, non-linear dynamic analysis (NLDA) is considered as a reference analysis method in seismic assessment.

Under the above premises, the project MARS largely introduces NLDAs for deriving fragility curves, especially as regards RC buildings. A cloud-like approach will be adopted made up of the following main steps:

1. Identification of building classes

2. Classification of building types

3. Simulated design of the selected building types

4. Modelling of the designed buildings

5. Selection of the Intensity Measure

6. Selection of representative ground-motion records

7. Non-linear dynamic analyses

8. Definition of the relationship "structural response-damage level"

9. Treatment of fragility curves dispersion

10. Generation of analytical fragility curves

It is worth noting that, in order to guarantee consistency and continuity between analytical and empirical results, a sanity check will be carried out by comparing and, eventually, calibrating them.

For some of the above steps, procedures already proposed in the literature will be essentially followed, while for some issues, that are the identification of building classes (2), the input selection (5-6), the uncertainty treatment (9) and the methodology adopted for deriving analytical fragility curves, which are in some ways common to all building types, some developments purposely being carried out in MARS will be described and discussed in the following sections.

\subsection{Identification of building classes}

In large-scale vulnerability studies through an analytical approach, a crucial aspect is the building inventory and, more specifically, the knowledge of the distribution of the attributes mainly affecting seismic vulnerability, among which: force resisting mechanism and material, age of construction, seismic design level, number of storeys, infills' arrangement and characteristics. In Italy, data on these attributes can be obtained from post-earthquake surveys, such as those collected in the Da.D.O. database (Dolce et al. 2019), or from specific research activities, such as those ones carried out in the above mentioned Work Package "WP2-CARTIS" (Zuccaro et al. 2015).

More in general, poor typological information is provided by the ISTAT census of the population and houses (ISTAT 2011). The Italian building stock amounts to about 12 million buildings, mostly with masonry structure (more than 7 million) and about 3.7 million with RC structure. Figure 5a shows that, due to the prevalence of masonry structures, almost half of the Italian buildings have 2 storeys (i.e. low-rise type). Nevertheless, more refined data deriving from local surveys (e.g. Chiauzzi et al. 2012; Da.D.O. database) reveal a significant town-to-town differences in terms of number of storeys. As an example, comparing the building inventory of Potenza and L'Aquila, that are similar in terms of total number of inhabitants and seismic hazard level, Figure 5b shows that the percentage of RC 


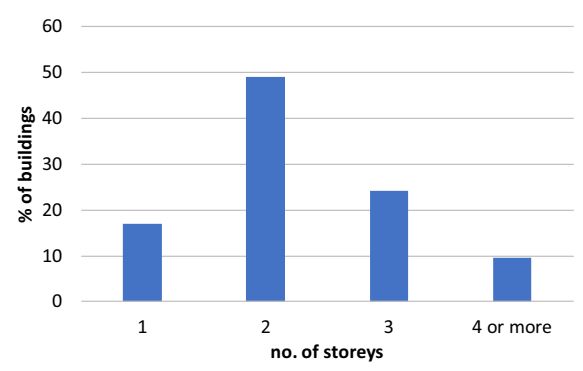

(a)

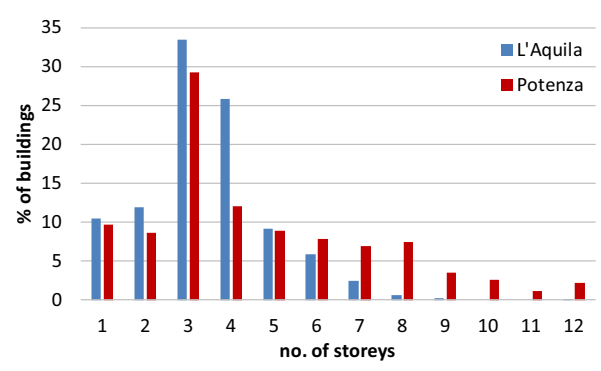

(b)

Fig. 5 a Distribution of N. of storeys in the Italian building stock (ISTAT census) b Distribution of N. of storeys in RC buildings: comparison between L'Aquila and Potenza building stock

Fig. 6 Distribution of construction periods of Italian RC and masonry buildings

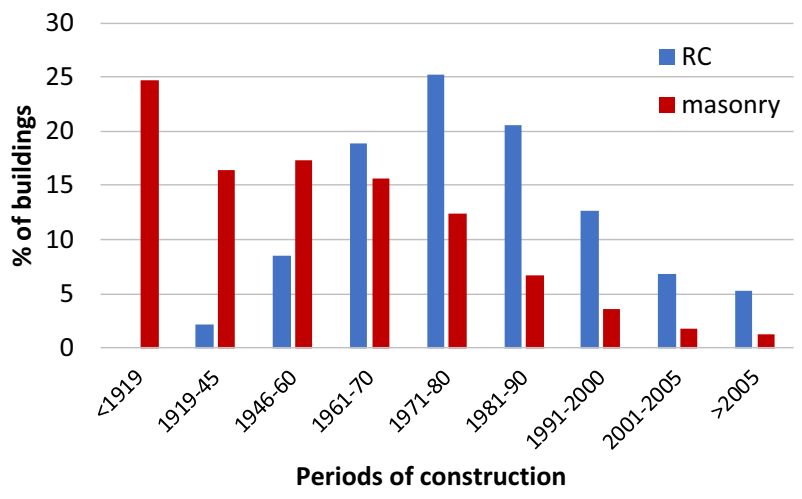

buildings in Potenza with a number of storeys greater than 6 is about $25 \%$, while this percentage is almost negligible for L'Aquila.

Information on the periods of construction is crucial to identify the different shares of buildings ascribable to different structural codes and design practices. To this purpose, Fig. 6 shows the percentages of masonry and RC buildings for different construction periods. In Italy masonry buildings were mostly realized until the end of the '70s. After, due to the higher speed of construction and fewer architectural restraints, RC buildings became the structural type (specifically moment resisting frames) mostly adopted in Italy, as well as in other EU countries.

Most of the existing residential buildings have been designed only for gravity loads (GLD buildings). In case of the seismic design of new buildings, for most of the classified territory, moderate seismic actions (i.e. horizontal loads equal to either $7 \%$ or $10 \%$ of the "seismic weight" within an allowable stresses approach), quite often without any ductile design criteria, have been used.

In the '70s, two fundamental laws (n. 1086, 5 November 1971; n. 64, 2 February 1974) were enforced to guarantee better construction quality of structures. Therefore, two macroperiods over the 1970s can be defined (i.e. pre- and post-1970), where post-1970 buildings have generally better materials' quality and design practice. The structural quality of buildings further increased in the '90s, when some design criteria (e.g. frames along both in-plan directions) introduced in the seismically classified area were adopted, frequently 
also in case of gravity load design, and more attention was generally paid to reinforcement details (e.g. Circular 65/1997).

Taking into account the well-known role of infill walls on seismic performance, especially in case of GLD buildings, the characteristics of infills' types and their changes over time need to be identified. In the construction practice, infills' characteristics were chosen considering the required thermal properties, then they are essentially related to the development of energy codes (Manfredi and Masi, 2014). It is worth underlining that analytical approaches enable to overcome the lack of data on infills peculiar to empirical approaches. Specifically, appropriate modelling of infills can better highlight the influence of different infill types on seismic performance.

Putting together the above remarks, and in accordance with the most relevant taxonomies (e.g. SYNER-G, Pitilakis et al. 2014; GEM, Brzev et al. 2013), analytical fragility curves for RC Italian buildings will be derived by considering the following main attributes (Fig. 7):

- Period of construction;

- Number of storeys;

- Infill arrangement;

- Code level.

Specifically, according to the ranges defined by ISTAT 2011, three periods will be considered for RC buildings, i.e. 1946-70, 1971-90, > 1991.

As for the number of storeys, previous studies (e.g., Masi et al. 2015) show that, in order to account for the main differences in structural characteristics (i.e. different plan layout) and expected seismic performance, Low-rise type (namely buildings with 1-2

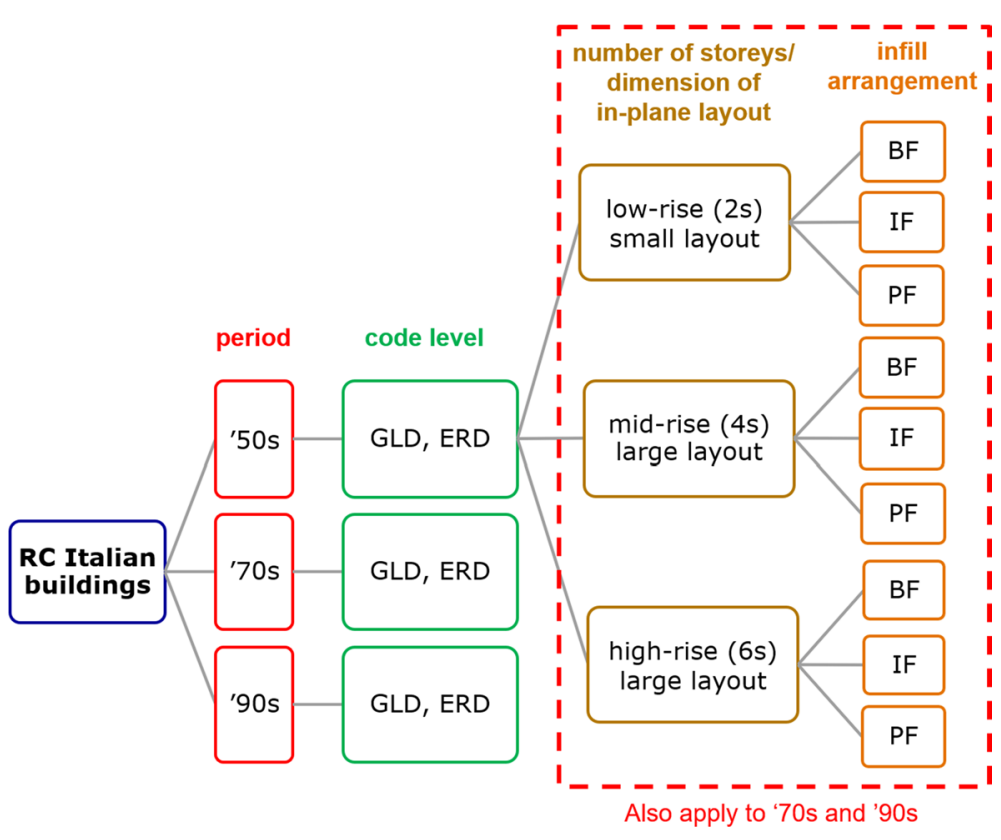

Fig. 7 RC building classes and types (note that BF types will be considered only for reference scope) 
storeys, Fig. 8a, d), Mid-rise (3-5, Fig. 8b, e) and High-rise ( $\geq 6$, Fig. 8c, e) need to be analysed. Further, the results related to these three building types will be properly elaborated according to the exposure classes defined by IRMA platform and ISTAT 2011.

As for infills' arrangement, Regularly Infilled-frame (IF) and Pilotis-frame (PF) types will be considered. Bare frame types (BF), where the presence of infills is totally neglected, will be also analysed simply as a reference for comparison.

Besides, two macro classes will be defined as a function of the code level, i.e. buildings designed only for gravity loads (GLD) and buildings with earthquake resistant design (ERD). For these latter, due to the large prevalence over the Italian territory until 2003, a building class including structures designed according to the 2nd seismic category (lateral forces equal to $7 \%$ of the seismic weight) will be considered.

Because the reconstruction process after past Italian earthquakes involved a considerable number of buildings in the affected areas (Dolce and Di Bucci 2017; Di Ludovico $2017 \mathrm{a}, \mathrm{b})$, strengthened structures will be also considered.

Finally, by considering the typical strengthening criteria provided in the current codes, also mitigated risk maps will be prepared and compared with the corresponding maps based on the current as-built vulnerability, in view of defining possible prevention strategies.

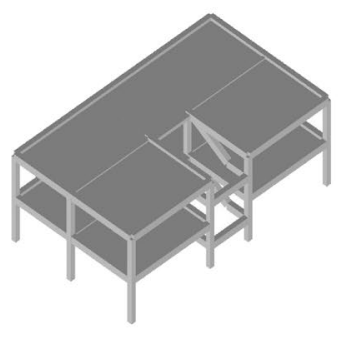

(a)

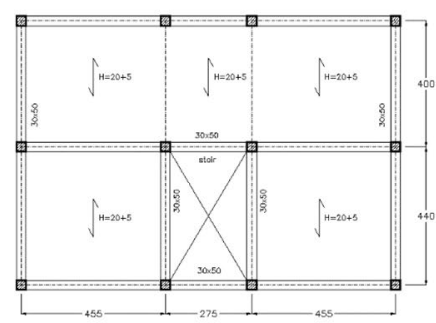

(d)

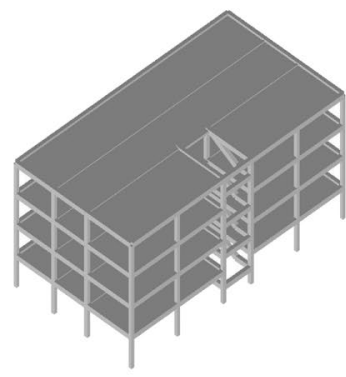

(b)

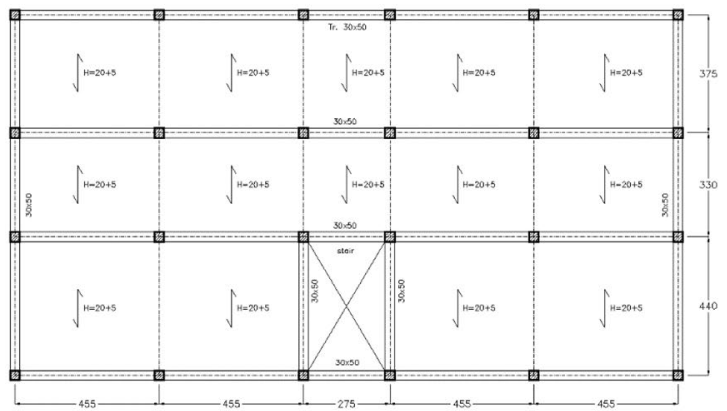

(e)

Fig. 8 3D view of 2 storey (a), 4 storey (b) and 6 storey (c), and in-plane layout of 2 storey (d), 4 storey and 6 storey (f) types 


\subsection{Seismic input selection for NLDAs}

When deriving fragility curves through non linear dynamic analyses (NLDAs), a crucial point is the selection of representative ground motion records. In order to achieve an adequate reliability in the fragility analyses, some issues have to be addressed, among which: (1) the selection criteria of earthquake records, (2) the required number of records, (3) the considered intensity measure, and (4) the scaling method (Bommer and Acevedo 2004; NIST 2011).

According to ATC-58-1 (FEMA 2018), it is necessary to select a number of signals (over a range of ground motion levels of interest) consistent with the hazard curve obtained from a probabilistic seismic hazard analysis for the area under study (Bazzurro and Cornell 1994). To this purpose, signals are usually selected from database of real earthquakes (e.g. Smerzini et al. 2014), or numerically generated in order to match target response spectra obtained from different approaches, such as the Uniform Hazard Spectrum (UHS) and the Conditional Mean Spectrum (CMS) (e.g. Lin et al. 2013).

UHS envelopes the results of seismic hazard analysis in order to provide spectral ordinates for each period of vibration having the same probability of exceedance (McGuire 2004). This approach has an inherent conservatism due to the fact that the spectral values at each period are not likely to occur all in a single event (e.g. Bommer et al. 2000; Iervolino and Manfredi 2008).

The Conditional Mean Spectrum (Baker 2011), as well as the Conditional Spectrum (CS, Abrahamson and Atik, 2010), provide the target spectrum as a function of the spectral acceleration (derived from the seismic hazard analysis) of a single specific period, while the other spectral ordinates are evaluated in terms of mean or distribution of intensities. Although both CMS and CS overcome some limitations of the UHS approach, they can lead to both site- and structure-specific signals, thus possibly introducing some difficulties in case of large scale analyses involving different sites and building types. In order to reduce these site-to-site and structure-to-structure dependences, updated procedures to obtain CS, incorporating multiple causal earthquakes (Lin et al. 2013) and adopting a sufficient Intensity Measure (IM) such as the averaged spectral acceleration, have been proposed by some researchers (e.g. Kohrangi et al. 2017). Note that a sufficient IM renders the seismic response independent of ground motion characteristics, such as magnitude and distance.

Several codes and guidelines suggest that the selected records should be consistent with the dominant earthquake properties, such as magnitude and site-to-source distance. Nevertheless, some studies (e.g. Iervolino and Cornell 2005) argue that spectral shape is a more important parameter.

The optimal number of signals to be adopted is still an open issue (Haselton et al. 2012). Generally, the best number is a compromise between the time for analysis execution and the required accuracy in defining each considered damage level (NIST, 2011). In order to get a reasonable accuracy of the mean value of structural response, some design codes require a few number of ground motions (e.g. minimum three signals according to ASCE/SEI 41-06 (2007), at least 7 signals in EuroCode 8 (CEN, 2004)). A far greater number of ground motions (e.g. at least 7 signals per 8 intensity levels according to ATC-58-1 (FEMA, 2018)) needs in case of fragility curves' derivation, where special attention has to be paid to response dispersion (Kiani et al. 2018). Besides, Baltzopoulos et al. (2019) point out that the appropriate number of ground 
motions is remarkably dependent on the site-specific hazard and influences the achievable level of accuracy.

The most important factor in selecting an appropriate IM is its efficiency, which is related to a reduced dispersion in the computation of the selected engineering demand parameter (EDP). Beyond the already cited sufficiency, other factors able to evaluate the goodness of the adopted intensity are: practicality, effectiveness, robustness and computability (Cornell et al. 2002). Although several IMs are available in the literature, Peak Ground Acceleration (PGA) and Spectral acceleration at the fundamental period value $\left(\mathrm{Sa}\left(\mathrm{T}_{1}\right)\right)$ are the most commonly used in fragility analyses. This mainly derives from the large availability of ground motion prediction equations (GMPEs) based on these IMs, contrarily to what happens with other IMs. However, it is worth noting that PGA and $\mathrm{Sa}\left(\mathrm{T}_{1}\right)$ have some limitations and can be poorly related to the non-linear response of building structures (Masi 2003; Haselton et al. 2012). Kazantzi and Vamvatisikos (2015) investigated sufficiency and efficiency of both single-period spectral values and several combinations of spectral accelerations in a wide range of period, finding that the best IM is obtained by the geometric mean of the spectral acceleration values across an appropriate period range (i.e. above and below the mean first-mode period of the considered building classes). An integral parameter, such as Housner Intensity, was considered by Masi et al. (2010, 2015) as an IM able to effectively represent the real damage potential of an earthquake. Finally, Gehl et al. (2015) showed that considering seismic parameters combining two IMs can determine a significant reduction of the scatter in the fragility function.

Although natural records from real earthquakes should be the main way to represent the complexity of ground shaking, several approaches to manipulate (i.e. scaling) ground motion signals in order to reach the heavier damage levels up to collapse are provided in the literature. They are generally based on a constant factor scaling in the time domain (e.g. Iervolino et al. 2010) or on spectral matching techniques (e.g. Abrahamson 1998). A comprehensive discussion of advantages/ drawbacks of both approaches can be found in the NIST (2011) report.

A specific task of MARS deals with the above issues (Task 4.2), mainly devoted to provide representative seismic signals for the reliable derivation of fragility curves in a cloudlike approach.

In these activities, the need to define fragility functions able to assess the seismic risk for all the Italian territory (and then across the site-to-site and the structure-to-structure dependence) accounting for the currently adopted IM by the IRMA platform, has been properly considered. As a result, real signals consistent with the Italian earthquake characteristics have been considered and analysed in terms of PGA.

As for IM selection, PGA has been eventually chosen finding the best compromise between good correlation with the non linear seismic response and practical constraints. These latter are mainly related to data available from the Italian hazard map and characteristics of the IRMA platform used for preparing the national risk assessment. Actually, although PGA is not the best IM in terms of both efficiency and sufficiency, it has a good practicality and does not depend on structural information of the specific building at hand (such as the period of vibration). Further, it permits to directly compare fragility curves derived from previous research projects and studies, where PGA is largely employed as IM.

More than one hundred unscaled (real) input motions with increasing intensity levels able to reach all the EMS-98 damage levels have been selected (Paolucci et al. 2020). A procedure purposely set up to select real records from a large dataset (Smerzini et al. 2014) has been used in the WP-MARS. Selection criteria are based on the overall spectral shape similarity to a target spectrum by weighting some parameters, e.g. spectrum 
intensities related to the range of vibration period consistent with the considered structural types. Code-conforming hazard spectra (DM 17/01/2018) have been considered as target and defined for different return periods and for two types of soil (i.e. stiff and soft soil representative of the categories $\mathrm{A} / \mathrm{B}$ and $\mathrm{C} / \mathrm{D}$, respectively, according to $\mathrm{DM}$ 17/01/2018). For higher intensity levels (i.e. PGA values higher than $0.5-0.6 \mathrm{~g}$ ), a spectral matching procedure of real recorded motions has been adopted. It is based on iterative scaling in the frequency domain until the response spectrum is approached within a given tolerance with the target spectrum.

Figures $9 \mathrm{a}$ and $\mathrm{b}$ show the PGA values relevant to the dataset of 125 signals on stiff soil for the two in-plan orthogonal components, $\mathrm{X}$ and $\mathrm{Y}$, highlighting unscaled and spectral matching records. Each PGA value has been plotted as a function of the geometric mean value obtained by considering the related pair of data (i.e. X and Y). For the unscaled subdataset, PGA values range from about 0.1 to $0.6 \mathrm{~g}$ while intensity values up to about $1.2 \mathrm{~g}$ refer to the spectral matching signals. It is worth specifying that, as a rule, the considered set of records has increasing values of the Housner intensity going from 0.15 to $3.2 \mathrm{~m}$.

\subsection{Uncertainty treatment}

Empirical approaches implicitly take into account different sources of uncertainty, such as the capacity variability within a given building (so-called intra-building variability) and within a building set or stock (so-called building-to-building variability). Besides, they take also into account site-effects of the ground motion related to the considered earthquake events. On the contrary, uncertainties in deriving fragility curves through analytical approaches need to be specifically identified and evaluated. Uncertainty types may vary significantly as a function of the selected analysis and modelling method. The major sources of uncertainty refer to: (1) the capacity of the considered prototype

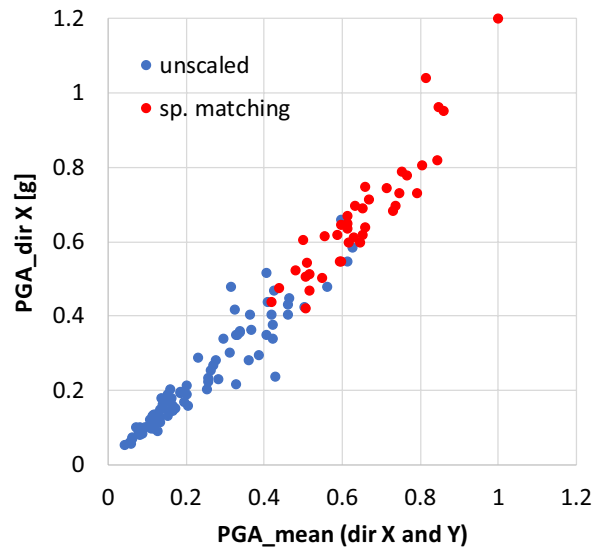

(a)

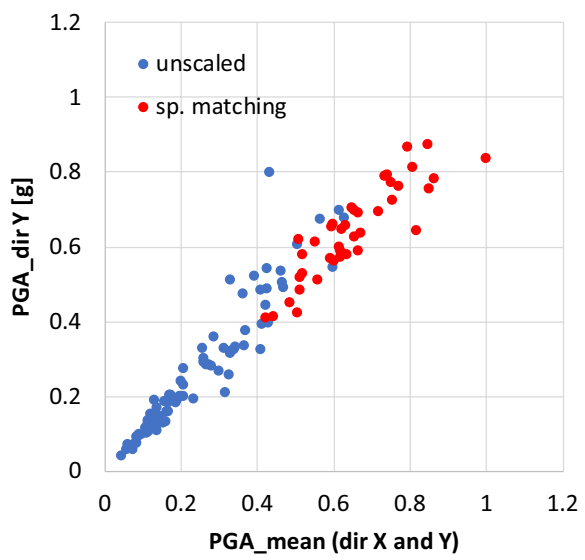

(b)

Fig. 9 PGA values related to both X (a) and Y (a) direction (note that, for both directions, PGA values have been plotted with respect to the geometric mean value obtained by considering the related pair of data (i.e. $\mathrm{X}$ and $\mathrm{Y})$ ) 
building, (2) the seismic demand at which the building is subjected to, and (3) the damage thresholds' definition (SYNER-G Project, Pitilakis et al. 2014).

Uncertainty in capacity accounts for both intra-building and building-to-building variability. It derives from different values of materials' properties, geometric configurations and dimensions, structural details and, finally, modelling approach adopted to simulate the structural response.

Uncertainty in demand accounts for the record-to-record variability related to different mechanisms of seismic source, path attenuation and site effects.

Finally, damage threshold uncertainty accounts for the definition of the limit levels, the choice of the damage model and its consistency with the type of analysis, the damage indicator used to represent the damage levels of a structure, and the correlation with the chosen intensity measure (Maio and Tsionis 2015).

Because most of the available approaches employs lognormal cumulative distribution functions for deriving fragility curves (Porter et al. 2007), standard deviation of the natural logarithm of the considered IM is used to describe the total variability associated to a given damage level. In this framework, each factor contributing to the overall uncertainty $\left(\beta_{\mathrm{TOT}}\right)$ is considered as independent, thus it is computed through a square root sum-of-the-squares (SRSS) rule, as follows:

$$
\beta_{T O T}=\sqrt{\beta_{D}^{2}+\beta_{C}^{2}+\beta_{D S}^{2}}
$$

where $\beta_{\mathrm{D}}$ accounts for the record-to-record variability, $\beta_{\mathrm{C}}$ is the uncertainty in the capacity of the structure, $\beta_{\mathrm{DS}}$ is the uncertainty in the definition of damage levels.

Uncertainty due to seismic demand is explicitly taken into account through the selection and scaling of an adequate number of ground motions in terms of an efficient IM. This source of variability is often considered the main source of variability, at least when the fragility curves of a specific building are evaluated. Typical values are in the range $0.4-0.5$ (e.g. Kwon and Elnashai 2006).

In order to numerically evaluate the capacity uncertainty, one or more parameters are considered random variables following a predefined probability distribution and, then, a set of values are propagated by means of Monte-Carlo or first-order second-moment techniques (e.g. Vamvatsikos and Fragiadakis, 2010). Several studies (e.g. D’Ayala and Meslem 2013; Porter et al. 2002, Lee et al., 2005) observed that capacity uncertainty has a low effect on the slight and moderate damage level. Instead, higher impact, comparable to that one related to demand uncertainty, can be found for the collapse state (Ibarra and Krawinkler 2003). O'Reilly and Sullivan (2018) carried out analyses in order to evaluate the uncertainty associated with different modelling parameters for Italian existing RC frames. Results show that modelling uncertainty is in the range 0.2-0.4, in accordance with other studies (Cornell et al. 2002; Ellingwood et al. 2007; Kappos et al. 2006; FEMA 2012). Liel et al. (2009) showed that modelling uncertainty can modify also the median value of fragility curves. Specifically, they found a reduction of the median value around $20 \%$.

As far as damage threshold uncertainty is concerned, according to several studies dealing with RC buildings (e.g. Kappos et al. 2006; FEMA 2018; Wen et al. 2004; Celik and Ellingwood 2010; Jeon et al. 2015), common values to be used in fragility analyses range from 0.25 to 0.4 , essentially derived from expert judgement. Summarizing, for the RC analytical fragility curves to be derived in MARS research activities, a SYNER-G-like approach will be adopted as for uncertainty treatment. Specifically, three sources of uncertainty, that are demand, capacity and damage level definition, will be considered according to Eq. 9. Specifically, record-to-record variability will be directly evaluated from non-linear 
dynamic analyses by considering the selected ground motion records (see Sect. 3.2). On the contrary, in order to limit the execution time required for explicitly evaluating uncertainty related to capacity, $\beta_{\mathrm{C}}$ will be assigned by adopting constant values drawn from the literature. With respect to the dispersion due to damage level definition, $\beta_{\mathrm{DS}}$, although it is partly comprised into the cloud-like approach, its value will be attributed also by expert judgment accounting for typical values obtained from the literature.

\subsection{Generation of analytical fragility curves}

For each NLDA carried out on the selected building types, the maximum drift value along the height (and by considering both in-plane directions) will be evaluated and referred to the PGA value of the corresponding accelerogram. In this way, PGA-drift points can be collected for all the considered accelerograms and then processed as a function of a properly defined structural parameter well correlated with damage. To this purpose, Table 5 reports the damage levels according to the EMS98 classification (Grünthal, 1998) and the relevant ranges of interstorey drift (median) values (IDR) adopted by Masi et al. (2015) for deriving the fragility curves of typical Italian buildings designed only for gravity loads (GLD). Starting from these values, additional values will be considered in order to take into account the role of the different code levels and, if necessary, the presence/consistency of infills.

Figure 10a shows (in logarithmic scale) the PGA-IDR points obtained for all accelerograms (A/B soil category) by considering a four-storey type (4s) with regularly arranged infills (IF), designed only for vertical loads according to '70s code. In the same figure, the above reported threshold values of IDR (see Table 5) for each damage level are also shown.

By considering the points falling into the different IDR ranges, the median and the logarithmic standard deviation of the PGA values related to each damage level can be evaluated. Starting from these values, the following expression for deriving fragility curves (e.g. FEMA 2018) is applied for each damage level:

$$
P(D k \mid P G A)=\Phi\left[\frac{1}{\beta_{D, D k}} \cdot \ln \left(\frac{P G A}{\overline{P G A}_{D k}}\right)\right] \quad k=1, \ldots, 5
$$

where $P(D k \mid P G A)$ is the probability of exceedance of the $k$-th damage level Dk given a PGA value, $\Phi$ is the standard normal (Gaussian) cumulative distribution function, $\beta_{\mathrm{D}, \mathrm{Dk}}$ and $P G A_{D k}$ denote the logarithmic standard deviation and median values, respectively.

Note that the above reported logarithmic standard deviation term $\left(\beta_{\mathrm{D}}\right)$ accounts for only the record-to-record variability as obtained from the NLDAs. In order to consider all

Table 5 Relationship between damage levels and interstorey drift values adopted for GLD buildings

\begin{tabular}{|c|c|c|c|c|c|c|}
\hline & DO & D1 & D2 & D3 & D4 & D5 \\
\hline \multirow{2}{*}{$\begin{array}{l}\text { EMS-98 } \\
\text { definition }\end{array}$} & 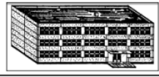 & 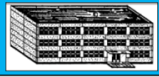 & 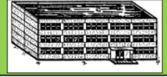 & 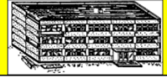 & 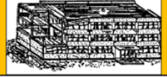 & 6 \\
\hline & $\begin{array}{l}S D=\text { null } \\
N S D=\text { null }\end{array}$ & $\begin{array}{l}\text { SD = null } \\
\text { NSD = slight }\end{array}$ & $\begin{array}{l}\text { SD = slight } \\
\text { NSD =moderate }\end{array}$ & $\begin{array}{l}\mathrm{SD}=\text { moderate } \\
\mathrm{NSD}=\text { heavy }\end{array}$ & $\begin{array}{l}\text { SD = heavy } \\
\text { NSD = very } \\
\text { heavy }\end{array}$ & Destruction \\
\hline $\begin{array}{l}\text { Interstorey } \\
\text { drift (\%) }\end{array}$ & $<0.1$ & $0.1-0.25$ & $0.25-0.5$ & $0.5-1.0$ & $1.0-2.5$ & $>2.5$ \\
\hline
\end{tabular}




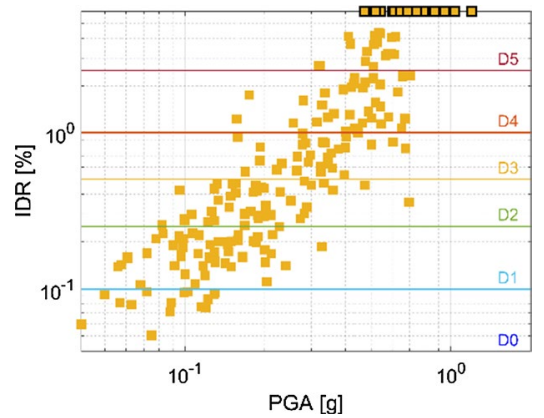

(a)

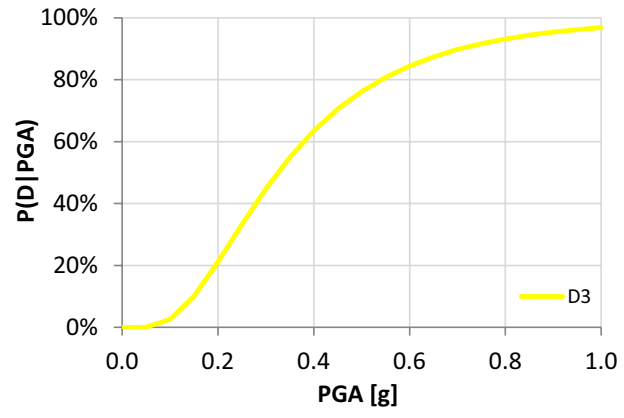

(b)

Fig. 10 PGA-drift points related to 4s-IF-'70s type (black marker edge refers to dynamic instability cases) (a) and the corresponding fragility curves related to damage level D3 (b)

sources of uncertainty as described at Sector 3.3 , the values related to capacity $\left(\beta_{\mathrm{C}}\right)$ and damage level definition $\left(\beta_{\mathrm{DS}}\right)$ uncertainty have to be added according to Eq. 9.

It is worth noting that D5 damage level refers to NLDA results assuming two possible collapse conditions, that is: (1) drift exceeds the considered threshold value (hereafter $\mathrm{C} 1$ case), and (2) dynamic instability (e.g. Villaverde 2007; Vamvatsikos and Cornell 2002) resulting in very large drift values or non-convergence of the analysis (hereafter $\mathrm{C} 2$ case). Both cases need to be considered in deriving the fragility curves. Specifically, by adapting the procedure reported in Jalayer et al. (2017), the two contributions to the conditional probability can be made explicit by using the total probability theorem, as follows:

$$
P(D 5 \mid P G A)=P\left(D 5 \mid P G A, C_{1}\right) \cdot\left(1-P\left(C_{2} \mid P G A\right)\right)+P\left(C_{2} \mid P G A\right)
$$

where $P\left(D 5 \mid P G A, C_{1}\right)$ is the conditional probability of having D5 damage level (given a certain PGA value) due to drift value exceeding the threshold value ( $\mathrm{C} 1$ case), computed by Eq. 10; $P\left(C_{2} \mid P G A\right)$ is the probability of occurrence of the dynamic instability case (C2) whose value can be predicted by a logistic regression model as a function of PGA (Jalayer et al. 2017).

Just to give some preliminary examples of fragility curves obtained by applying the proposed procedure, in Fig. 11 the sets of fragility curves related to the 4-storey type designed according to '70s code with either IF (Fig. 11a) or PF (Fig. 11b) infill arrangement, are shown.

As expected, IF type shows better performance than PF one. For example, for damage level D3, the median value is $0.32 \mathrm{~g}$ for IF and $0.19 \mathrm{~g}$ for PF, with a similar logarithmic standard deviation value equal to about 0.62 .

Finally, to better understand the differences between the two sets of FCs, the damage distributions related to a seismic event with $\mathrm{PGA}=0.2 \mathrm{~g}$ are displayed in Fig. 11c. Results show that damage found in the building type with PF configuration is significantly higher when more than $10 \%$ of buildings would suffer total collapse (D5), while a lower percentage (about $2 \%$ ) would suffer collapse in case of regularly arranged infills (IF type). 


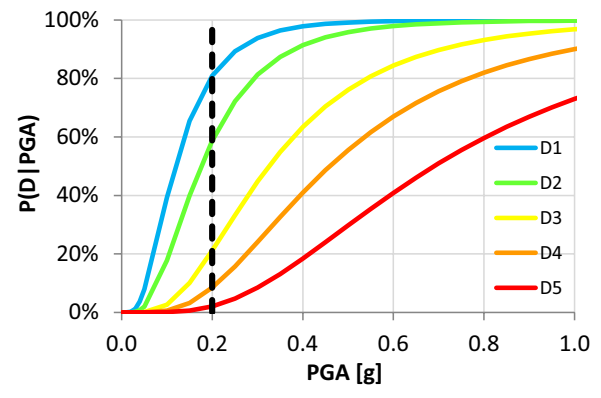

(a)

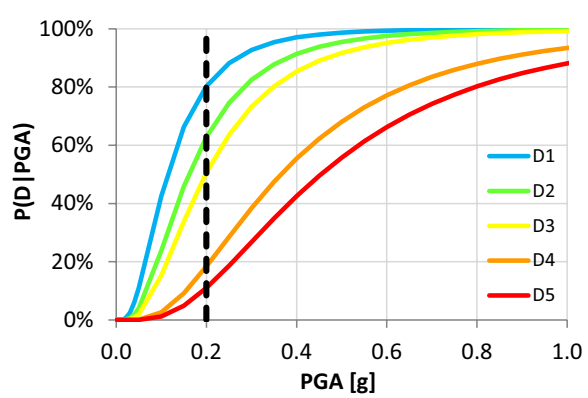

(b)

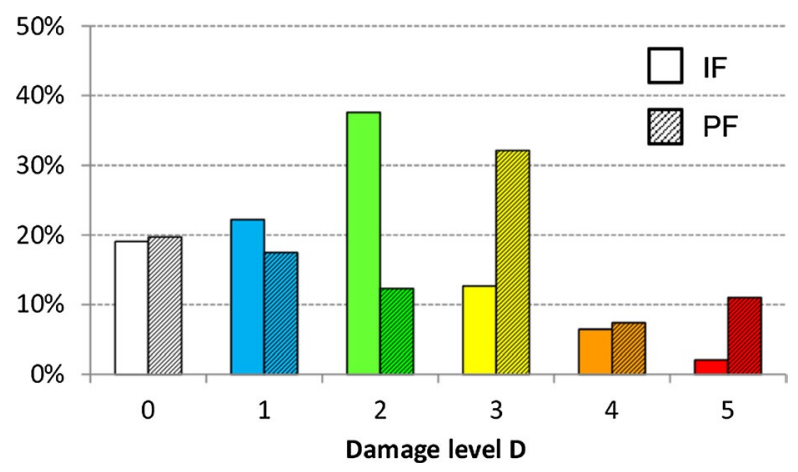

(c)

Fig. 11 Fragility curves for 4s-IF-'70s (a) and 4s-PF-'70s type (b). Damage distributions related to a seismic event with $\mathrm{PGA}=0.2 \mathrm{~g}(\mathbf{c})$

\section{Seismic risk analysis of special buildings: schools and churches}

The NRA made in 2018 with the platform IRMA considered only the residential building stock, with data aggregated at municipality scale at statistical level, without reference to single buildings.

The WP2-MARS, besides the already described progress for the seismic risk assessment of the residential building stock ( $\$ 2, \S 3)$, has started the analysis of two typologies of special buildings:

- School buildings, which are particularly relevant from the social point of view, because strategic for the education of the young generations and for their life safety;

- Churches, which are relevant because they are part of the cultural heritage in Italy, but are also important from the social point of view and critical for the life safety as buildings subject to crowding.

To this end, together with Eucentre, two dedicated platforms have been created, which include the inventory of georeferenced buildings taken from available and certified institutions: 
- IRMA school buildings: 49.351 buildings (16.520 RC, 10.416 masonry and the other are mainly mixed masonry-RC) from the inventory of the Italian Ministry of Education, with general information (structural material, number of stories, gross area, etc.) and structural features integrated from other available databases (e.g. Borzi e al. 2013);

- IRMA churches: two big databases have been merged (Calderini 2020): 67.014 from the Italian Episcopal Conference CEI (BeWeB—https://beweb.chiesacattolica.it/edifi cidiculto), 39.223 churches from the Ministry of Cultural Heritage (http://vincoliinr ete.beniculturali.it); information refers to construction age, architectonic typology and presence of artistic assets (relevant for the loss analysis); many relevant information are available in textual form and should be codified.

The analysis of building portfolios is aimed to get aggregated results on the vulnerability and risk, without the intention to evaluate at the scale of each single building. The reason is that the vulnerability is derived from few structural information that allows to use models valid at statistical scale. The platforms show the buildings (schools or churches) in the precise location and with the related information, as well as the estimated damage. However, the damage scenario is also aggregated at municipality (and also provincial/regional) scale, in order to have a clear and effective representation of the risk of the portfolio, consistently with a risk assessment at national scale.

Regarding the platform IRMA school buildings, the MARS vulnerability model described in $\$ 2$ is adopted. The taxonomy available from the database is more detailed than that of residential buildings because, in addition to the information of the ISTAT types (also the mixed masonry-RC structure is present), other features are generally available: horizontal diaphragms, roof structure, plan area. The combination of many options of the school taxonomy determines a large amount of school sub-types, but not all of them are numerically relevant and, anyhow, it would be difficult to assign a different set of fragility curves to each of them. The problem is that, differently from the ISTAT inventory, many pieces of information are missing, thus, by using a complete subdivision into sub-types, a lot of schools would be not classified. Therefore, the platform IRMA school buildings allows for a flexible and incremental classification in which only some of taxonomy information are considered. In this way, fragility curves may be assigned to almost all schools in the portfolio, only by rough information (e.g. masonry/RC/mixed and the number of stories), and then specific fragility curves may be introduced for sub-types that are numerically relevant in the database and for which vulnerability models are available.

Regarding the platform IRMA churches, specific vulnerability models have to be adopted, because of the distinctive features with respect to residential and school buildings. Some models are available in the literature, due to the interest aroused after the extensive damage survey in Umbria-Marche earthquake, 1997 (Lagomarsino and Podestà 2004). Vulnerability models have been proposed, mainly based on the empirical approach and considering the macroseismic intensity as intensity measure (Guerreiro et al. 2000; da Porto et al. 2012; Leite et al. 2013; Sorrentino et al. 2014; De Matteis et al. 2016; Marotta et al. 2018; Penna et al. 2019; Lagomarsino et al. 2019; Canuti et al. 2019; Cescatti et al. 2020). Fragility curves may be derived from these models, analogously to what was done for the residential buildings (Lagomarsino et al. 2021). However, one of the aims of the WP2-MARS is to collect all the damage data observed on churches in the last 25 years in Italy, with survey form originally proposed after the Umbria-Marche earthquake (1997) and then formally adopted by the Civil Protection 
Department (G.U. 2006). The webgis tools "DaDO churches" is going to be implemented, in collaboration with Eucentre and the Civil Protection Department, analogously to the already available webgis Da.D.O. (Dolce et al. 2019). These damage data are very useful to derive fragility curves through empirical approaches.

\section{Final remarks}

The need to reduce the many natural risks requires an ever-increasing capacity to measure and therefore quantify them in terms of social and economic losses.

In particular for seismic risk, which is the subject of this paper, the peculiarities of the seismic behaviour of buildings pose important problems in establishing a correlation between the intensity of future earthquakes and the damage they produce, with all the uncertainties inherent in the knowledge of the conditions that determine the hazard and the vulnerability. To these are added those related to the exposed assets (people, goods and economic activities, cultural heritage, etc.) as well as the social implications of a disaster, which make the assessment of indirect losses and socio-economic impact particularly complex.

If, on the one hand, the modelling capabilities of a complex reality, such as the seismic response of the built heritage, are constantly growing in line with scientific developments and the exponential growth of data processing and storage capabilities, on the other hand, this need for quantification clashes with the inevitable limitation of knowledge of the reality of the built heritage and with the enormous number of diverse elements of which it is made up and of which only a few characteristics are known. For this reason there is ample room for improvement in risk estimates, in the face of fervent scientific activity on the subjects of seismic hazard, vulnerability and exposure.

The effort made in 2018 to carry out a national seismic risk assessment of the housing stock has produced undoubtedly important results. This is also because they are the fruit of a common goal by numerous research groups that have tried to arrive, through a systematic interaction, at a confident seismic risk scenario, made by the combination of those obtained by the different models, as requested by the Civil Protection Department that had commissioned the project. With the new DPC-ReLUIS seismic risk assessment project at national level, developed within the Work Package called WP4-MARS, the intention is manifold.

First of all, the aim is to improve the risk assessment of the housing stock, in continuity with the 2018 assessment, through improved methodologies for the assessment of fragility curves. These methodologies use and integrate both empirical data, in particular the damage data of past earthquakes, of which Italy is particularly rich, and the ability to process and simulate the real behaviour of buildings, especially those for which the empirical data is lacking and which are too different from the buildings for which the empirical data is available. It is obvious that, in this promiscuous use of empirical data and data deriving from numerical elaborations, particular attention shall be paid to the consistency and continuity of results, always keeping in mind that empirical reality dominates over modelling.

Moreover, the aim is also to expand the assessment framework, extending it to other types of buildings, which can be called special types, for which the fragility curves valid for ordinary buildings are unsuitable, due to the different structural characteristics, both for general architectural configuration and for specific requirements that had to be met for the functions performed there. This is the case, particularly in this work, for schools 
and churches. Of both, knowledge is available, albeit very limited, of each building, to which the most suitable fragility curve can be associated. Obviously, also in this case the limitation of the knowledge of the real building heritage is a fact that strongly affects the evaluation of the individual building, so even for these two building portfolios the results can only be statistical and therefore will be returned at a territorial level, i.e. for groups of buildings, and not individually.

In the logic of an overall risk assessment, reference should be made also to transport infrastructure works, in particular the typically most vulnerable elements such as bridges and viaducts. Also for these, with a considerable capacity for simulation using numerical models, there is a lack of knowledge of their construction characteristics, in particular road infrastructures. Although not covered in the paper, a similar approach to that adopted for buildings is being applied to them, but the results may be available in a longer time frame.

A key point, which has also been the hallmark of NRA-2018, is to enable different research groups to develop their models and carry out their assessments in such a way as to pool and combine different knowledge and results, leading to a single risk model that brings together the best knowledge and is widely accepted in the scientific community.

To this end, in the wake of what was done for NRA-2018, the common IRMA advanced processing platform, version 2.0, has been further implemented and extended to other types. In this way it will be possible, through shared tools and databases to express vulnerability and exposure, and with reference to the same hazard model, the immediate comparison between the different exposure/vulnerability models and between the different risk results, and their most appropriate combination.

Acknowledgements This article has been developed under the financial support of the Italian Department of Civil Protection, within the ReLUIS-DPC 2019-21 Research Project, which is gratefully acknowledged. Further, the authors would like to acknowledge that several other researchers actively participate to the work package MARS activities working on the topics included in this article, with a special acknowledgement to Barbara Borzi, Roberto Paolucci, Giulio Zuccaro, Serena Cattari and Chiara Calderini.

Funding Open access funding provided by Università degli Studi della Basilicata within the CRUI-CARE Agreement. This article has been developed under the financial support of the Italian Department of Civil Protection, within the ReLUIS-DPC 2019-21 Research Project.

\section{Compliance with ethical standards}

Conflicts of interest The authors declare that there is no conflict of interest.

Open Access This article is licensed under a Creative Commons Attribution 4.0 International License, which permits use, sharing, adaptation, distribution and reproduction in any medium or format, as long as you give appropriate credit to the original author(s) and the source, provide a link to the Creative Commons licence, and indicate if changes were made. The images or other third party material in this article are included in the article's Creative Commons licence, unless indicated otherwise in a credit line to the material. If material is not included in the article's Creative Commons licence and your intended use is not permitted by statutory regulation or exceeds the permitted use, you will need to obtain permission directly from the copyright holder. To view a copy of this licence, visit http://creativecommons.org/licenses/by/4.0/. 


\section{References}

Abrahamson NA (1998) Non-stationary spectral matching program RSPMATCH. Pacific Gas and Electric Company Internal Report

Abrahamson NA, Al Atik L (2010) Scenario spectra for design ground motions and risk calculation. Proceedings of the 9th U.S. National and 10th Canadian Conference on Earthquake Engineering, July 25-29, 2010, Toronto, Ontario, Canada, Paper No 1896

ASCE (2007) Seismic rehabilitation of existing buildings, ASCE/SEI 41-06. American Society of Civil Engineers, Reston, Virginia

Baltzopoulos G, Baraschino R, Iervolino I (2019) On the number of records for structural risk estimation in PBEE. Earthq Eng Struct Dyn 48:489-506. https://doi.org/10.1002/eqe.3145

Baker JW (2011) Conditional mean spectrum: tool for ground motion selection. J Struct Eng 137(3):322331. https://doi.org/10.1061/(ASCE)ST.1943-541X.0000215

Bazzurro P, Cornell CA (1994) Seismic hazard analysis of nonlinear structures I: methodology. J Struct Eng 120(11):3320-3344

Bommer JJ, Scott SG, Sarma SK (2000) Hazard-consistent earthquake scenario. Soil Dyn Earthq Eng 19(4):219-231

Bommer JJ, Acevedo AB (2004) The use of real earthquake accelerograms as input to dynamic analysis. J Earthq Eng 8:43-91

Borzi B, Pinho R, Crowley H (2008) Simplified pushover-based vulnerability analysis for large scale assessment of RC buildings. Eng Struct 30(3):804-820

Borzi B, Ceresa P, Faravelli M, Fiorini E, Onida M (2013) Seismic Risk Assessment of Italian School Buildings. In: Papadrakakis M, Fragiadakis M, Plevris V (eds) Computational Methods in Earthquake Engineering. Computational Methods in Applied Sciences, vol 30. Springer, Dordrecht

Borzi B, Onida M, Faravelli M, Polli D, Pagano M, Quaroni D, Cantoni A, Speranza E, Moroni C (2020) IRMA platform for the calculation of damages and risks of residential buildings. Bull Earthq Eng. https://doi.org/10.1007/s10518-020-00924-x

Braga F, Dolce M, Liberatore D (1982) A statistical study on damaged buildings and an ensuing review of the MSK-76 scale, Proceedings of the Seventh European Conference on Earthquake Engineering, Athens, 431-450

Brzev S, Scawthorn C, Charleson AW, Allen L, Greene M, Jaiswal K, Silva V (2013) GEM Building Taxonomy Version 2.0. GEM Technical Report 2013-02V1.0.0, pp. 188, GEM Foundation, Pavia, Italy, Doi: https://doi.org/10.13117/GEM.EXP-MOD.TR2013.02

Canuti C, Carbonari S, Dall'asta A, Dezi L, Gara F, Leoni G, Morici M, Petrucci E, Prota A, Zona A (2019) Post-earthquake damage and vulnerability assessment of churches in the Marche region struck by the 2016 Central Italy Seismic Sequence. Int J Archit Heritage. https://doi.org/10.1080/15583 058.2019 .1653403

Calderini C (2020) Definizione e compilazione di database delle chiese presenti sul territorio italiano, relativi alla vulnerabilità sismica e al danno subito, da integrare nelle piattaforme IRMA e DaDO sviluppate da Eucentre/DPC. Report ReLUIS 4.8.P2.UR2 (UniGEa) (in Italian)

Calvi GM, Pinho R (2004) LESSLOSS, a European integrated project on risk mitigation for earthquakes and landslides. Research report ROSE 2004/02. IUSS Press, ISBN:88-7358-020-3

Calvi GM, Pinho R, Magenes G, Bommer JJ, Restrepo-Vélez LF, Crowley H (2006) Development of seismic vulnerability assessment methodologies over the past 30 years. ISET J Earthq Technol 43(3):75-104

Cattari S, Degli Abbati S, Ferretti D et al (2014) Damage assessment of fortresses after the 2012 Emilia earthquake (Italy). Bull Earthq Eng 12:2333-2365

Celik OC, Ellingwood BR (2010) Seismic fragilities for non-ductile reinforced concrete frames-role of aleatoric and epistemic uncertainties. Struct Saf 32(2010):1-12

CEN (2004) European Standard ENV 1998-1-1/2/3, Eurocode 8: design provisions for earthquake resistance of structures_-part I: general rules. Technical Committee 250/SC8, Comité Européen de Normalisation, Brussels

Cescatti E, Salzano P, Casapulla C, Ceroni F, da Porto F, Prota A (2020) Damages to masonry churches after 2016-2017 Central Italy seismic sequence and definition of fragility curves. Bull Earthq Eng 18(1):297-329

Chiauzzi L, Masi A, Mucciarelli M, Vona M, Pacor F, Cultrera G, Gallovič F, Emolo A (2012) Building damage scenarios based on exploitation of Housner intensity derived from finite faults ground motion simulations. Bull Earthq Eng 10(2):517-545

Cornell CA (1968) Engineering seismic risk analysis. Bull Seismol Soc Am 58(1583-1606):1968

Cornell CA, Jalayer F, Hamburger RO, Foutch DA (2002) Probabilistic basis for 2000 SAC federal emergency management agency steel moment frame guidelines. J Struct Eng (ASCE) 128(4):526-533 
D’Ayala D, Meslem A (2013) Derivation of analytical fragility functions considering modelling uncertainties. Proceedings of the 11th International Conference on Structural Safety and Reliability, New York, USA

D’Ayala D, Meslem A, Vamvatsikos D, Porter K, Rossetto T (2015) Guidelines for Analytical Vulnerability Assessment—Low/Mid-Rise, Vulnerability Global Component Project (available at www.globalquak emodel.org)

Da Porto F, Silva B, Costa C, Modena C (2012) Macro-scale analysis of damage to churches after earthquake in Abruzzo (Italy) on April 6, 2009. J Earthq Eng 16(6):739-758

Da Porto F et al. (2020) Comparative analysis of the fragility curves for Italian masonry and RC buildings, Bull Earthq Eng, Under Review

De Matteis G, Criber E, Brando G (2016) Damage probability matrices for Three-Nave Masonry Churches in Abruzzi after the 2009 L'Aquila Earthquake. Int J Archit Heritage 10(2-3):120-145

Del Gaudio C, Ricci P, Verderame GM, Manfredi G (2015) Development and urban-scale application of a simplified method for seismic fragility assessment of RC buildings. Eng Struct 91:40-57. https://doi. org/10.1016/j.engstruct.2015.01.031

Del Gaudio C, Di Ludovico M, Polese M, Manfredi G, Prota A, Ricci P, Verderame GM (2020) Seismic fragility for Italian RC buildings based on damage data of the last 50 years. Bull Earthq Eng 18:45474548. https://doi.org/10.1007/s10518-020-00890-4

Di Ludovico M, Prota A, Moroni C, Manfredi G, Dolce M (2017a) Reconstruction process of damaged residential buildings outside the historical centres after L'Aquila earthquake-part I: "light damage"” reconstruction. Bull Earthq Eng. https://doi.org/10.1007/s10518-016-9877-8

Di Ludovico M, Prota A, Moroni C, Manfredi G, Dolce M (2017b) Reconstruction process of damaged residential buildings outside historical centres after the L'aquila earthquake-part II: "'heavy damage"” reconstruction. Bull Earthq Eng. https://doi.org/10.1007/s10518-016-9979-3

Dolce M (1996) Vulnerability evaluation and damage scenarios. Proceedings of US-Italian Workshop on Seismic Evaluation and Retrofit, December 1996, New York City

Dolce M, Masi A, Marino M, Vona M (2003). Earthquake damage scenarios of the building stock of Potenza (Southern Italy) including site effects, Bulletin of Earthquake Engineering, Kluwer, 1/2003

Dolce M, Kappos A, Masi A, Penelis G, Vona M (2006) Vulnerability assessment and earthquake scenarios of the building stock of Potenza (Southern Italy) using the Italian and Greek methodologies. Eng Struct 28(2006):357-437

Dolce M, Goretti A (2015) Building damage assessment after the 2009 Abruzzi earthquake. Bull Earthq Eng 13:2241-2264

Dolce M, Di Bucci D (2017) Comparing recent Italian earthquakes. Bull Earthq Eng 15:497-533. https:// doi.org/10.1007/s10518-015-9773-7

Dolce M, Speranza E, Giordano F, Borzi B, Bocchi F, Conte C, Di Meo A, Faravelli M, Pascale V (2019) Observed damage database of past Italian earthquakes: the Da.D.O webgis. Bollettino di Geofisica Teorica e Applicata 60(2):141-164

Dolce M, Prota A, Borzi B, da Porto F, Lagomarsino S, Magenes G, Moroni C, Penna A, Polese M, Speranza E, Verderame GM, Zuccaro G (2020) Seismic risk assessment of residential buildings in Italy. Bull Earthq Eng. https://doi.org/10.1007/s10518-020-01009-5

Donà M, Carpanese P, Follador V, Sbrogiò L, da Porto F (2020) Mechanics-based fragility curves for Italian residential URM buildings. Bull Earthq Eng. https://doi.org/10.1007/s10518-020-00928-7

Ellingwood BR, Celik OC, Kinali K (2007) Fragility assessment of building structural systems in MidAmerica. Earthq Eng Struct Dyn 36(13):1935-1952

Federal Emergency Management Agency (FEMA), (2012) Hazus-MH 2.1 technical manual: earthquake model, developed by Federal Emergency Management Agency, Mitigation Division, Washington, D.C.

FEMA P-58-1 (2018) Seismic Performance Assessment of Buildings, Volume 1-Methodology. Applied Technology Council, Redwood City, California

Gehl P, Douglas J, Seyedi D (2015) Influence of the number of dynamic analyses on the accuracy of structural response estimates. Earthq Spectra 31(1):2015. https://doi.org/10.1193/102912EQS320M

Grunthal G (1998) European Macroseismic Scale. Chaiers du Centre Européen de Géodynamique et de Séismologie, Vol. 15, Luxembourg

G.U. no. 55, Direttiva P.C.M. 23 febbraio (2006) Approvazione dei modelli per il rilevamento dei danni, a seguito di eventi calamitosi, ai beni appartenenti al patrimonio monumentale (in Italian)

Guerreiro L, Azevedo J, Proença J, Bento R, Lopes M (2000) Damage in ancient churches during the 9th of July 1998 Azores earthquake. Proceedings of XII World Conference on Earthquake Engineering. January 30-February 4, 2000, Auckland, New Zealand 
Haselton CB, Whittaker AS, Hortacsu A, Baker JW, Bray J, Grant DN (2012) Selecting and scaling earthquake ground motions for performing response-history analyses. Proceeding of the 15th WCEE, Lisboa 2012

Ibarra L, Krawinkler H (2003) Global collapse of frame structures under seismic excitations. Blume Center TR 152, Stanford University

Iervolino I, Cornell CA (2005) Record selection for nonlinear seismic analysis of structures. Earthq Spectra 21(3):685-713

Iervolino I, Manfredi G (2008) A review of ground motion record selection strategies for dynamic structural analysis. In: Bursi OS, Wagg DJ (eds) Modern testing techniques of mechanical and structural systems CISM courses and lectures 502. Springer, Berlin

Iervolino I, Galasso C (2010) Cosenza E (2010) REXEL: computer aided record selection for code-based seismic structural analysis. Bull Earthq Eng 8(2):339-362

Italian Civil Protection Department (2018) National Risk Assessment 2018. Overview of the potential major disasters in Italy. Updated December 2018

ISTAT, Italian National Institute of Statistics (2011) $15^{\circ}$ Censimento della popolazione e delle abitazioni, available at http://www.istat.ithttp://www.istat.it

Jalayer F, Cornell CA (2009) Alternative non-linear demand estimation methods for probability-based seismic assessments. Earthq Eng Struct Dyn 38:951-972

Jalayer F, Ebrahimian H, Miano A, Manfredi G (2017) Sezen H (2017) Analytical fragility assessment using un-scaled ground motion records. Earthq Eng Struct Dyn 46(15):2639-2663

Jeon JS, Lowes LN, DesRoches R, Brilakis I (2015) Fragility curves for non-ductile reinforced concrete frames that exhibit different component response mechanisms. Eng Struct 85(2015):127-143

Kazantzi AK, Vamvatsikos D (2015) Intensity measure selection for vulnerability studies of building classes. Earthq Eng Struct Dyn 44:2677-2694. https://doi.org/10.1002/eqe.2603

Kappos AJ, Panagopoulos G, Panagiotopoulos C et al (2006) A hybrid method for the vulnerability assessment of R/C and URM buildings. Bull Earthq Eng 4:391-413. https://doi.org/10.1007/s1051 8-006-9023-0

Kiani J, Camp C, Pezeshk S (2018) On the number of required response history analyses. Bull Earthq Eng $16: 5195-5226$

Kwon OS, Elnashai A (2006) The effect of material and ground motion uncertainty on the seismic vulnerability curves of RC structure. Eng Struct 28(2006):289-303

Kohrangi M, Vamvatsikos D, Bazzurro P (2017) Site dependence and record selection schemes for building fragility and regional loss assessment. Earthq Eng Eng Dyn 46(10):1625-1643

Lagomarsino S, Podestà S (2004) Seismic vulnerability of ancient churches. Part 2: statistical analysis of surveyed data and methods for risk analysis. Earthq Spectra 20:395-412

Lagomarsino S, Giovinazzi S (2006) Macroseismic and mechanical models for the vulnerability and damage assessment of current buildings. Bull Earthq Eng 4:415-443

Lagomarsino S (2012) Damage assessment of churches after L'Aquila earthquake (2009). Bull Earthq Eng 10:73-92

Lagomarsino S, Cattari S (2015) Seismic Performance of Historical Masonry Structures Through Pushover and Nonlinear Dynamic Analyses. In: Ansal A (ed) Perspectives on European Earthquake Engineering and Seismology Geotechnical Geological and Earthquake Engineering. Springer, Cham. https:// doi.org/10.1007/978-3-319-16964-4_11

Lagomarsino S, Cattari S, Ottonelli D, Giovinazzi S (2019) Earthquake damage assessment of masonry churches: proposal for rapid and detailed forms and derivation of empirical vulnerability curves. Bull Earthq Eng 17(6):3327-3364

Lagomarsino S, Cattari S, Ottonelli D (2021) The heuristic vulnerability model: fragility curves for masonry buildings. Bull Earthq Eng. https://doi.org/10.1007/s10518-021-01063-7

Law n. 1086, 5 November 1971. Norme per la disciplina delle opere di conglomerato cementizio armato, normale e precompresso ed a struttura metallica. G.U. n. 321, 21-12-1971 (in Italian)

Law n. 64, 2 February 1974. Provvedimenti per le costruzioni con particolari prescrizioni per le zone sismiche. G.U. n. 76, 21-03-1974 (in Italian)

Lee TH, Mosalam KM (2005) Seismic demand sensitivity of reinforced concrete shear wall building using FOSM method. Earthq Eng Struct Dyn 34:1719-1736

Leite J, Lourenco PB, Ingham JM (2013) Statistical assessment of damage to churches affected by the 2010-2011 canterbury (New Zealand) earthquake sequence. J Earthq Eng 17(1):73-97

Liel AB, Haselton CB, Deierlein GG, Baker JW (2009) Incorporating modeling uncertainties in the assessment of seismic collapse risk of buildings. Struct Saf 31(2009):197-211

Lin T, Harmsen SC, Baker JW, Luco N (2013) Conditional spectrum computation incorporating multiple causal earthquakes and ground motion prediction models. Bull Seismol Soc Am 103(2A):1103-1116 
Maio R, Tsionis G (2016) Seismic fragility curves for the European building stock: review and evaluation of analytical fragility curves. EUR 27635 EN. Doi: https://doi.org/10.2788/586263

Marotta A, Sorrentino L, Liberatore D, Ingham JM (2018) Seismic risk assessment of New Zealand unreinforced Masonry Churches using statistical procedures. Int J Archit Heritage 12(3):448-464

Masi A (2003) Seismic vulnerability assessment of gravity load designed R/C frames. Bull Earthq Eng 1(3):371-395

Masi A, Vona M, Mucciarelli M (2010) Selection of natural and synthetic accelerograms for seismic vulnerability studies on RC frames. J Struct Eng. https://doi.org/10.1061/(ASCE)ST.1943-541X.209

Masi A, Digrisolo A, Manfredi V (2015) Fragility curves of gravity-load designed RC buildings with regularity in plan. Earthq Struct 9(1):1-27

Masi A, Chiauzzi L, Santarsiero G et al (2019) Seismic response of RC buildings during the Mw 6.0 August 24, 2016 Central Italy earthquake: the Amatrice case study. Bull Earthq Eng 17:5631-5654

McGuire R (2004) Seismic Hazard and Risk Analysis. EERI Monograph Earthquake Engineering Research Institute, Oakland, California

Ministry of Public Work, Circular n. 65/AA.GG., 10 April 1997. Istruzioni per l'applicazione delle Norme tecniche per le costruzioni in zone sismiche di cui al decreto ministeriale16 gennaio 1996. G.U. n. 97 , 28 April 1997

Ministrial Decree 17 January 2018 (DM), NTC 2018. Aggiornamento delle "Norme Tecniche per le Costruzioni". GU n. 42, 20 February 2018

Mouroux P, Le Brun B (2006) Presentation of RISK-UE project. Bull Earthq Eng 4:323-339

NIST (2011). Selecting and scaling earthquake ground motions for performing response-history analyses. Report for the National Institute for Standards and Technology NIST GCR 11-917-15

O'Reilly GJ, Sullivan TJ (2018) Quantification of modelling uncertainty in existing Italian RC frames. Earthq Eng Struct Dyn 47:1054-1074. https://doi.org/10.1002/eqe.3005

Paolucci R, Ozcebe AG, Smerzini C, Masi A, Manfredi V (2020) Selection and spectral matching of recorded ground motions for earthquake engineering analysis, available at http://143.225.144.186:5000/

Penna A, Calderini C, Sorrentino L, Carocci CF, Cescatti E, Sisti R, Borri A, Modena C, Prota A (2019) Damage to churches in the 2016 central Italy earthquakes. Bull Earthq Eng 17(10):5763-5790

Pitilakis K, Crowley H, Kaynia AM (2014) Introduction in: SYNER-G: Typology Definition and Fragility Functions for Physical Elements at Seismic Risk, Buildings, Lifelines, Transportation Networks and Critical Facilities, Pitilakis K, Crowley H, Kaynia AM (editors) Springer Science+Business Media Dordrecht 2014

Polese M, Verderame GM, Mariniello C, Iervolino I, Manfredi G (2008) Vulnerability analysis for gravity load designed RC buildings in Naples-Italy. J Earthq Eng 12(S2):234-245

Porter KA, Beck JL, Shaikhutdinov RV (2002) Sensitivity of building loss estimates to major uncertain variables. Earthq Spectra 18(4):719-743

Porter K, Kennedy R, Bachman R (2007) Creating fragility functions for performance-based earthquake engineering. Earthq Spectra 23(2):471-489

Rossetto T, Elnashai A (2003) Derivation of vulnerability functions for European-type RC structures based on observational data. Eng Struct 25(10):1241-1263

Rossetto T, D’Ayala D, Ioannou I, Meslem A (2014). Evaluation of existing fragility curves in: SYNER-G: Typology Definition and Fragility Functions for Physical Elements at Seismic Risk, Buildings, Lifelines, Transportation Networks and Critical Facilities, Pitilakis K, Crowley H, Kaynia AM (editors) Springer Science+Business Media Dordrecht 2014

Rota M, Penna A, Strobbia C (2008) Processing Italian damage data to derive typological fragility curves. Soil Dyn Earthq Eng 28(10-11):933-947

Rosti A, Rota M, Penna A (2020) Empirical fragility curves for Italian URM buildings. Bull Earthq Eng. https://doi.org/10.1007/s10518-020-00845-9

Rosti A, Del Gaudio C, Rota M, Ricci P, Di Ludovico M, Penna A, Verderame GM (2020) Empirical fragility curves for Italian residential RC buildings. Bull Earthq Eng. https://doi.org/10.1007/s10518-02000971-4

Silva V, Crowley H, Varum H, Pinho R, Sousa R (2014) Evaluation of analytical methodologies used to derive vulnerability functions. Earthq Eng Struct Dyn 43:181-204

Smerzini C, Galasso C, Iervolino I, Paolucci R (2014) Ground motion record selection based on broadband spectral compatibility. Earthq Spectra 30(4):1427-1448

Sorrentino L, Liberatore L, Decanini LD, Liberatore D (2014) The performance of churches in the 2012 Emilia earthquakes. Bull Earthq Eng 12(5):2299-2331

Stucchi M, Meletti C, Montaldo V, Crowley H, Calvi GM, Boschi E (2011) Seismic hazard assessment (2003-2009) for the Italian building code. Bull Seismol Soc Am 101:1885-1911

Vamvatsikos D, Cornell CA (2002) Incremental dynamic analysis. Earthq Eng Struct Dyn 31(3):491-514 
Vamvatsikos D, Fragiadakis M (2010) Incremental dynamic analysis for estimating seismic performance sensitivity and uncertainty. Earthq Eng Struct Dyn 39:141-163

Villaverde R (2007) Methods to assess the seismic collapse capacity of building structures: state of the art. J Struct Eng 133(1):57-66

Wen YK, Ellingwood BR, Bracci J (2004) Vulnerability function framework for consequence-based engineering. MAE Center Project DS-4 Report

Zuccaro G, Dolce M, De Gregorio D, Speranza E, Moroni C (2015) La scheda CARTIS per la Caratterizzazione Tipologico-Strutturale dei Comparti Urbani costituiti da edifice ordinary: valutazione dell'esposizione in analisi di rischio sismico. Proceedings of the 34th GNGTS, Trieste, 2015, available at http://www3.ogs.trieste.it/gngts/files/2015/S23/Riassunti/Zuccaro.pdf (in Italian)

Zuccaro G, Perelli FL, De Gregorio D, Cacace F (2020) Empirical vulnerability curves for Italian masonry buildings: evolution of vulnerability model from the DPM to curves as a function of acceleration. Bull Earthq Eng. https://doi.org/10.1007/s10518-020-00954-5

Publisher's Note Springer Nature remains neutral with regard to jurisdictional claims in published maps and institutional affiliations. 